\title{
General cutting dynamics model for five-axis ball-end milling operations
}

DOI:

$10.1115 / 1.4047625$

\section{Document Version}

Accepted author manuscript

Link to publication record in Manchester Research Explorer

\section{Citation for published version (APA):}

Li, J., Kilic, Z. M., \& Altintas, Y. (2020). General cutting dynamics model for five-axis ball-end milling operations. Journal of Manufacturing Science and Engineering, 1-25. https://doi.org/10.1115/1.4047625

\section{Published in:}

Journal of Manufacturing Science and Engineering

\section{Citing this paper}

Please note that where the full-text provided on Manchester Research Explorer is the Author Accepted Manuscript or Proof version this may differ from the final Published version. If citing, it is advised that you check and use the publisher's definitive version.

\section{General rights}

Copyright and moral rights for the publications made accessible in the Research Explorer are retained by the authors and/or other copyright owners and it is a condition of accessing publications that users recognise and abide by the legal requirements associated with these rights.

\section{Takedown policy}

If you believe that this document breaches copyright please refer to the University of Manchester's Takedown Procedures [http://man.ac.uk/04Y6Bo] or contact uml.scholarlycommunications@manchester.ac.uk providing relevant details, so we can investigate your claim.

\section{OPEN ACCESS}




\title{
General cutting dynamics model for five-axis ball-end milling operations
}

\author{
Jianhui Li ${ }^{a, b, 1}$, Z. Murat Kilic ${ }^{c}$, Yusuf Altintas ${ }^{b, *}$ \\ ${ }^{a}$ State Key Laboratory for Manufacturing Systems Engineering, Xi'an Jiaotong University, Xi'an, Shaanxi, 710054, China. \\ ${ }^{b}$ Manufacturing Automation Laboratory, Department of Mechanical Engineering, The University of British Columbia, BC, V6T 1Z4, Canada. \\ ${ }^{c}$ Department of Mechanical, Aerospace and Civil Engineering, The University of Manchester, Manchester, M13 9PL, United Kingdom.
}

Keywords: five-axis machine tools, milling process, chatter stability, forced vibration

\begin{abstract}
Five-axis ball-end milling is used extensively to machine parts with sculptured surfaces. This paper presents the general cutting dynamics model of ball-end milling process for machine tools with different five-axis configurations. The structural dynamics of both the tool and workpiece are considered for the prediction of chatter stability at each tool location along the tool path. The effects of tool-workpiece engagement (TWE) and tool axis orientation are included in the model. By sweeping the spindle speeds, the chatter-free spindle speeds are selected followed by the prediction of forced vibrations in five-axis milling of thin-walled, flexible parts. The proposed model has been experimentally illustrated to predict the chatter stability and forced vibrations on a table-tilting five-axis CNC machine tool.
\end{abstract}

\section{1) Introduction}

Five-axis ball-end milling processes are widely used in machining complex parts such as dies, molds and aerospace parts ${ }^{[1]}$. The flexibility of thin-walled parts such as gas turbine blades and slender end mills lead to both chatter and forced vibrations which hinder the machining productivity and dimensional quality of parts ${ }^{[2]}$. Chatter occurs due to the generation of chip thickness during machining operation ${ }^{[3]}$. The chip thickness oscillates at the chatter frequency and grows exponentially until a saturation limit (i.e. tool jumping out of cut). The resulting cutting forces and vibrations also grow proportional to the chip, hence may damage the tool, part and spindle bearings. The chatter is avoided by predicting stability lobes either in frequency $[4,5]$ or discrete-time domain [6,7]. The prediction of cutting stability in three-axis milling process primarily depends on the cutting force coefficients, structural dynamic parameters of the workpiece and machine tool itself at the cutting area, tool geometry and cutting conditions (i.e. spindle speed and cutting depth.).

Altintas et al. ${ }^{[8]}$ proposed an analytical model to predict the stability in the three-axis ball-end milling process which considers the structural dynamics of tool and workpiece in two mutually orthogonal directions (i.e., feed and normal directions). They did not consider the variation of dynamics along the tool path. Zhang et al. ${ }^{[9]}$ presented a method to predict the frequency response functions (FRFs) of tool center point at arbitrary spindle orientations by transforming the FRFs measured in three orthogonal postures of the spindle. They coupled the tool dynamics with the spindle using the receptance coupling substructure analysis (RCSA) ${ }^{[10]}$, and observed large differences in the FRFs measured at different postures of the spindle which affect the machining stability. Furthermore, the varying orientation of tool axis in five-axis ball-end milling process increases the complexity of the TWE geometry along the tool path ${ }^{[11]}$.

\footnotetext{
* Corresponding author. Tel.: +1 (604)822-5622; Fax: +1 (604)822-2403. E-mail addresses: altintas@mech.ubc.ca (Y. Altintas).

1 The author is a PhD student of Xi'an Jiaotong University, and a visiting student at the University of British Columbia.
} 


\begin{tabular}{|c|c|c|c|}
\hline \multicolumn{4}{|c|}{ Nomenclature } \\
\hline TWE & tool-workpiece engagement & $\psi\left(z_{k}\right)$ & lag angle at axial height $z_{k}$ \\
\hline FRFs & frequency response functions & $R_{0}$ & nominal radial of the tool \\
\hline TCP & tool center point & $R\left(z_{k}\right)$ & local cutter radial at axial height $z_{k}$ \\
\hline TCS & tool coordinate system & $i_{0}$ & nominal helix angle of the tool \\
\hline WCS & workpiece coordinate system & $i\left(z_{k}\right)$ & local helix angle at axial height $z_{k}$ \\
\hline $\mathrm{ECS}$ & engagement coordinate system & $d z$ & height of an axial disk elements of the tool \\
\hline LCS & local radial, tangential, and axial coordinate system & $z_{k}$ & axial height of axial element $k$ on the tool \\
\hline $\mathbf{P}_{\mathrm{TCP}}$ & position vector of TCP in WCS & $d b\left(z_{k}\right)$ & cutting width of axial element $k$ \\
\hline $\mathbf{O}$ & tool axis vector in WCS & $d S\left(z_{k}\right)$ & curved cutting edge segment of axial element $k$ \\
\hline${ }^{w} \mathbf{T}_{t}$ & homogeneous transformation matrix from TCS to WCS & $\kappa\left(z_{k}\right)$ & axial immersion angle of axial element $k$ \\
\hline${ }^{w} \mathbf{R}_{t}$ & rotational transformation matrix from TCS to WCS & $h_{j}\left(z_{k}, t\right)$ & chip thickness of axial element $k$ on flute $j$ \\
\hline${ }^{e} \mathbf{R}_{w}$ & rotational transformation matrix from WCS to ECS & $h_{s, j}\left(z_{k}, t\right)$ & static component of chip thickness \\
\hline${ }^{e} \mathbf{R}_{t}$ & rotational transformation matrix from TCS to ECS & $h_{d, j}\left(z_{k}, t\right)$ & dynamic component of chip thickness \\
\hline${ }^{e} \mathbf{R}_{l}$ & rotational transformation matrix from LCS to ECS & \multicolumn{2}{|c|}{$d \mathbf{F}_{\mathrm{LCS}, j}^{k}\left(z_{k}, t\right)$ force vector of axial element $k$ on flute $j$ in LCS } \\
\hline$\omega_{1}, \omega_{2}$ & two rotary vectors of five-axis machine tools & \multicolumn{2}{|c|}{$d \mathbf{F}_{\mathrm{ECS}, j}^{k}\left(z_{k}, t\right)$ force vector of axial element $k$ on flute $j$ in ECS } \\
\hline$s_{1}, s_{2}$ & two binary parameters before rotary vectors & $\mathbf{n}_{j}\left(z_{k}, t\right)$ & normal vector at axial height $z_{k}$ on flute $j$ in ECS \\
\hline$\theta_{1}, \theta_{2}$ & two rotation angles of five-axis machine tools & $\mathbf{A}_{j}\left(z_{k}, t\right)$ & directional matrix of axial element $k$ on flute $j$ \\
\hline $\boldsymbol{f}_{\mathrm{TCP}}(i)$ & feed vector of TCP on TWE $(i)$ in WCS & $\mathbf{A}_{j, k, 0}$ & average item of periodic coefficient matrix \\
\hline$f, f(i)$ & nominal feed rate, nominal feed rate on $\operatorname{TWE}(i)$ & $\Omega$ & spindle speed \\
\hline $\boldsymbol{f}_{T}\left(z_{k}, i\right)$ & feed vector at axial height $z_{k}$ on $\operatorname{TWE}(i)$ in ECS & $\omega_{T}$ & tooth passing frequency \\
\hline $\boldsymbol{f}_{L}\left(z_{k}, i\right)$ & linear feed vector at axial height $z_{k}$ on TWE $(i)$ in ECS & $T_{t}$ & tooth passing period \\
\hline $\boldsymbol{f}_{A}\left(z_{k}, i\right)$ & angular feed vector at axial height $z_{k} \operatorname{TWE}(i)$ in ECS & $N_{z}$ & number of axial disk element along the tool axis \\
\hline $\boldsymbol{\Delta}_{t}$ & vibration vector of the tool & $N_{t}$ & number of flute of the tool \\
\hline $\boldsymbol{\Delta}_{w}$ & vibration vector of the workpiece & $\Delta \theta_{f}(i)$ & tool axis rotation angle between two adjacent TWEs \\
\hline $\boldsymbol{\Delta}_{t w}$ & relative vibration vector between the tool and workpiece & $\Delta t_{f}(i)$ & elapsed time between two adjacent TWEs \\
\hline $\mathbf{F}_{t}, \mathbf{F}_{w}$ & force vector on the tool, force vector on the workpiece & $\omega_{f}(i)$ & average angular speed between two adjacent TWEs \\
\hline $\boldsymbol{\Phi}_{t}$ & FRFs matrix of the tool in TCS & $\mathbf{q}_{f}(i)$ & rotary axis between two adjacent TWEs around TCP \\
\hline $\boldsymbol{\Phi}_{w}$ & FRFs matrix of the workpiece in WCS & $K_{r c}, K_{t c}, K_{a c}$ & radial, tangential, axial shearing force coefficients \\
\hline $\boldsymbol{\Phi}_{t w}$ & relative FRFs matrix between tool and workpiece in ECS & $K_{r e}, K_{t e}, K_{a e}$ & radial, tangential, axial edge force coefficients \\
\hline$\phi_{k}^{s t}, \phi_{k}^{e x}$ & start, exit immersion angle of axial element $k$ on the TWE & $f_{n}$ & nature frequency \\
\hline$\phi_{j}\left(z_{k}, t\right)$ & radial immersion angle at axial height $z_{k}$ on flute $j$ & $\zeta_{m}$ & modal damping ratio \\
\hline$g\left[\phi_{j}\left(z_{k}, t\right.\right.$ & $t)]$ angle-dependent binary parameter & $k_{m}$ & modal stiffness \\
\hline
\end{tabular}

The distribution of the engagement on the ball-end part of the tool where cutting takes place is highly affected by the orientation of the tool axis. Consequently, the chip thickness, cutting forces and stability of the five-axis ball-end milling are affected by the engagement as well as the tool axis orientation. Ozturk and Budak ${ }^{[12]}$, and recently Tuysuz and Altintas ${ }^{[13]}$ studied the effect of tool orientation on the chatter stability of ball end milling operations. Sun and Altintas ${ }^{[14]}$ presented a method to avoid chatter in five-axis ball-end milling by searching chatter-free tool axis orientations when material removal rate and the shape of TWE are kept the same. However, the past studies did not consider the generalized kinematics that could cover any machine tool configuration. The prediction of forced vibrations in five axis ball end milling on any five-axis machine configuration has not been reported in the literature. The past research mainly 
focused on the chatter stability of ball-end milling operations. While the process must be chatter-free, the relative forced vibrations between the tool and workpiece must be as small as possible to obtain a smooth surface finish as demonstrated in a three axis milling of thin-walled structures by Ringgaard et al ${ }^{[15]}$.

This paper presents a general cutting dynamics model for five-axis ball-end milling. The kinematics between tool and workpiece is modeled using screw theory which can handle the five-axis machine tools with different configurations as presented in Section 2). The dynamic cutting force model and the chatter stability criterion at each tool location along the tool path are presented in Section 3). The prediction of forced vibrations in time and frequency domains for stable five-axis ball-end milling process is presented in Section 4). The simulation results and experimental validation of the proposed model are analyzed in Section 5). The paper is concluded in Section 6).

\section{2) Coordinate transformations in five-axis machining}

The dynamics of machine tools and workpiece, the cutting force, and the relative vibration between the tool and workpiece need to be modeled in the same coordinate system. The FRFs of the tool and the workpiece are measured in the tool coordinate system (TCS) $O_{t} \hat{x}_{t} \hat{y}_{t} \hat{z}_{t}$ and the workpiece coordinate system (WCS) $O_{w} \hat{x}_{w} \hat{y}_{w} \hat{z}_{w}$ respectively, while the NC program is generated in the WCS by the CAM systems. The WCS is fixed to the workpiece in machining, and the TCS is fixed to the spindle. These coordinate systems are demonstrated on our experimental QUASER UX600 A-C type table-tilting five-axis machine tool ${ }^{[16]}$ (Figure 1). 


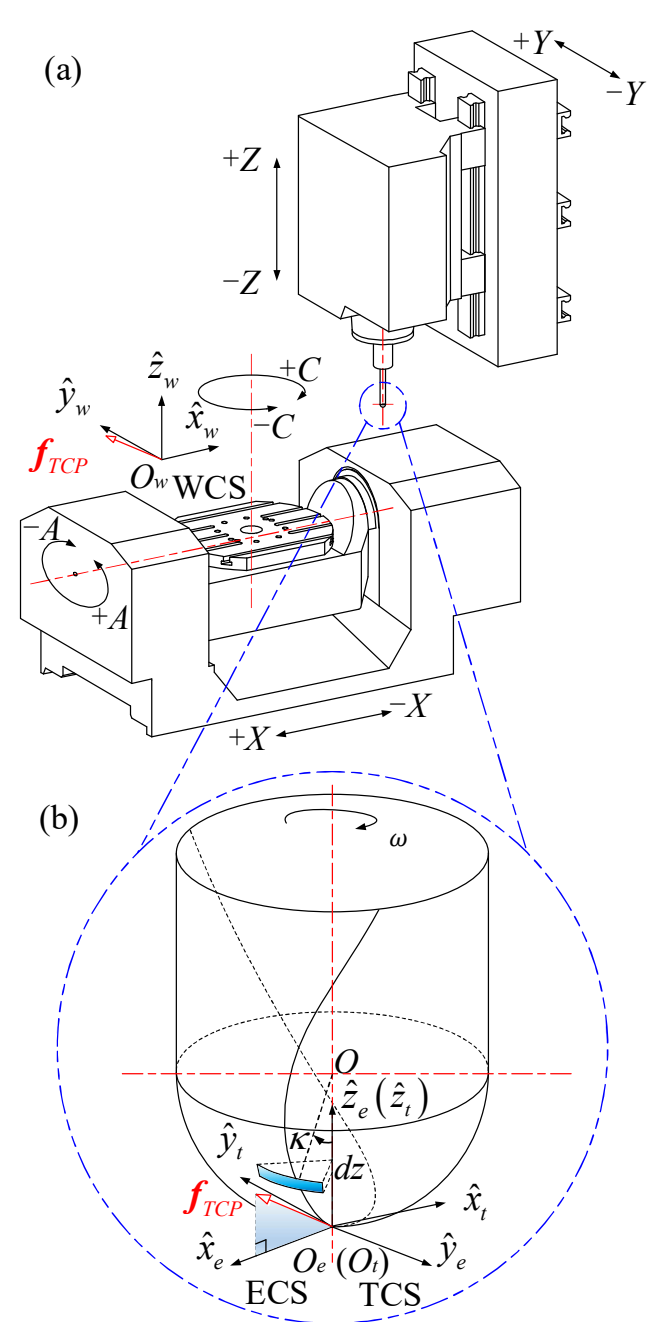

Figure 1 A-C type table-tilting five-axis machine tool. (a) Global view of the machine tool. (b) Partial enlarged view of the tool.

\section{1) Transformation from TCS to WCS}

The posture, the position and orientation of the tool relative to the workpiece mounted on machine tool, varies along the tool path in five-axis machining operations.

Five-axis NC programs contain the position $(x, y, z)_{\mathrm{TCP}}$ of tool center point in WCS and the tool axis vector $\left(o_{x}, o_{y}, o_{z}\right)$, which can be expressed as:

$$
\left\{\mathbf{P}_{\mathrm{TCP}}, \mathbf{O}\right\}_{\mathrm{WCS}}=\left\{(x, y, z)_{\mathrm{TCP}},\left(o_{x}, o_{y}, o_{z}\right)\right\}_{\mathrm{WCS}}
$$

However, Eq. (1) only describes the position of $O_{t}$ and the orientation of $\hat{z}_{t}$ in WCS, which is not sufficient to define the transformation matrix between TCS and WCS. To solve this problem, the kinematic model of five-axis machine tool with specific configuration and the initial posture at the home position are required.

Most conventional five-axis kinematic models are based on Denavit-Hartenberg ${ }^{[17]}$ representation, which uses fewer parameters but reference frames attached to each link following special rules of assignment ${ }^{[18]}$. As a results, Denavit-Hartenberg representation is difficult to be generalized for various five-axis machine tool configurations. 
Yang and Altintas ${ }^{[19]}$ developed a generalized kinematic model of five-axis machine tools using screw theory, no link reference frames but the initial posture is necessary, which is suitable for describing the general kinematics of five-axis machine tools.

The initial offset vector from WCS to TCS at the machine tool's home position are defined as ${ }^{w} \mathbf{p}_{t}(0)=\left[\begin{array}{lll}x_{0} & y_{0} & z_{0}\end{array}\right]^{T}$, while the initial orientation of TCS in WCS is defined by a 3 by 3 rotational matrix: ${ }^{w} \mathbf{R}_{t}(0)$. The homogeneous transformation matrix of TCS relative to WCS at machine tool's home position can be expressed as:

$$
{ }^{w} \mathbf{T}_{t}(0)=\left[\begin{array}{cc}
{ }^{w} \mathbf{R}_{t}(0) & { }^{w} \mathbf{p}_{t}(0) \\
0 & 1
\end{array}\right]
$$

According to the generalized kinematic model established in ${ }^{[19]}$, for the A-C type table-tilting five-axis machine tool shown in Figure 1, the homogeneous transformation matrix of TCS relative to WCS can be expressed as:

$$
{ }^{w} \mathbf{T}_{t}\left(\theta_{X}, \theta_{A}, \theta_{C}, \theta_{Y}, \theta_{Z}\right)=e^{-\left[\xi_{C}\right] \theta_{C}} \cdot e^{-\left[\xi_{A}\right] \theta_{A}} \cdot e^{-\left[\xi_{X}\right] \theta_{X}} \cdot e^{\left[\xi_{Y}\right] \theta_{Y}} \cdot e^{\left[\xi_{Z}\right] \theta_{Z}} \cdot{ }^{w} \mathbf{T}_{t}(0)
$$

where $\xi_{i}(i=C, A, X, Y, Z)$ and $\theta_{i}(i=C, A, X, Y, Z)$ are screw axes and motion commands, respectively. The definition of the screw axis $\boldsymbol{\xi}_{i}$ is provided in Appendix A.

The motion of translational axes has no effect on the orientation of tool axis relative to WCS, hence the homogeneous transformation matrix in Eq. (3) can be substituted by the rotational transformation matrix of TCS relative to WCS as:

$$
{ }^{w} \mathbf{R}_{t}\left(\theta_{A}, \theta_{C}\right)=e^{-\left[\boldsymbol{\omega}_{C}\right] \theta_{C}} \cdot e^{-\left[\omega_{A}\right] \theta_{A}} \cdot{ }^{w} \mathbf{R}_{t}(0)
$$

where $\boldsymbol{\omega}_{C}=[0,0,-1]^{T} ; \boldsymbol{\omega}_{A}=[-1,0,0]^{T}$, because these two rotary axes are mounted on the table side of the machine tool.

The kinematics model in Eq. (4) can be generalized to five-axis machine tools with different configurations. Let $\boldsymbol{\omega}_{1}$ and $\boldsymbol{\omega}_{2}$ are defined as the unit rotary vector of the first rotary axis close to the workpiece, and the second rotary axis close to the tool. $\theta_{1}$ and $\theta_{2}$ are the rotation angles of first and second rotatory axes, respectively. $s_{1}$ and $s_{2}$ are binary parameters which depend on whether the rotatory axis is mounted on the table side $\left(s_{i}=-1, i=1,2\right)$ or on the spindle side $\left(s_{i}=+1, i=1,2\right)$. As the general form of Eq.(4), the rotational transformation matrix of TCS relative to WCS for general five-axis machine tools is expressed as:

$$
{ }^{w} \mathbf{R}_{t}\left(\theta_{1}, \theta_{2}\right)=e^{s_{1}\left[\omega_{1}\right] \theta_{1}} \cdot e^{s_{2}\left[\omega_{2}\right] \theta_{2}} \cdot{ }^{w} \mathbf{R}_{t}(0)
$$

The rotation angles $\left(\theta_{1}, \theta_{2}\right)$ in Eq. (5) need to be calculated by the inverse kinematics of the specific five-axis configuration, the initial tool orientation, and the present tool orientation which read from the NC program. This inverse kinematics problem has a closed-form solution developed by Paden and Kahan by using screw theory ${ }^{[20]}$.

\section{2) Transformation between WCS and Engagement Coordinate System (ECS)}

The chatter stability and forced vibration analysis are modeled in the engagement coordinate system (ECS) along the tool path ${ }^{[14]}$. As shown in Figure 1, the $\mathrm{Z}$ direction of TCS and ECS are always fixed to the tool axis. But for ECS, its X direction is aligned with the projection of feed direction onto the normal plane of tool axis and Y direction is perpendicular to the tool axis and the feed in ECS where the machining process is modeled. As TWE varies and feed direction changes along the tool path, TWE on the tool is projected to ECS, and process is simulated at discrete locations along the tool path ${ }^{[21]}$.

For each TWE, the tool is divided into discrete axial elements along the tool axis. TWE information is described in ECS with the start immersion angle $\phi_{k}^{s t}$ and exit immersion angle $\phi_{k}^{e x}$ of the cutting flutes at 
axial height $z_{k}$ along the tool axis for the discrete axial element $k$, as shown in Figure $2^{[22]}$. The TWE information throughout the five-axis tool path is obtained from the virtual machining software MACHpro ${ }^{\mathrm{TM}}$ [23].

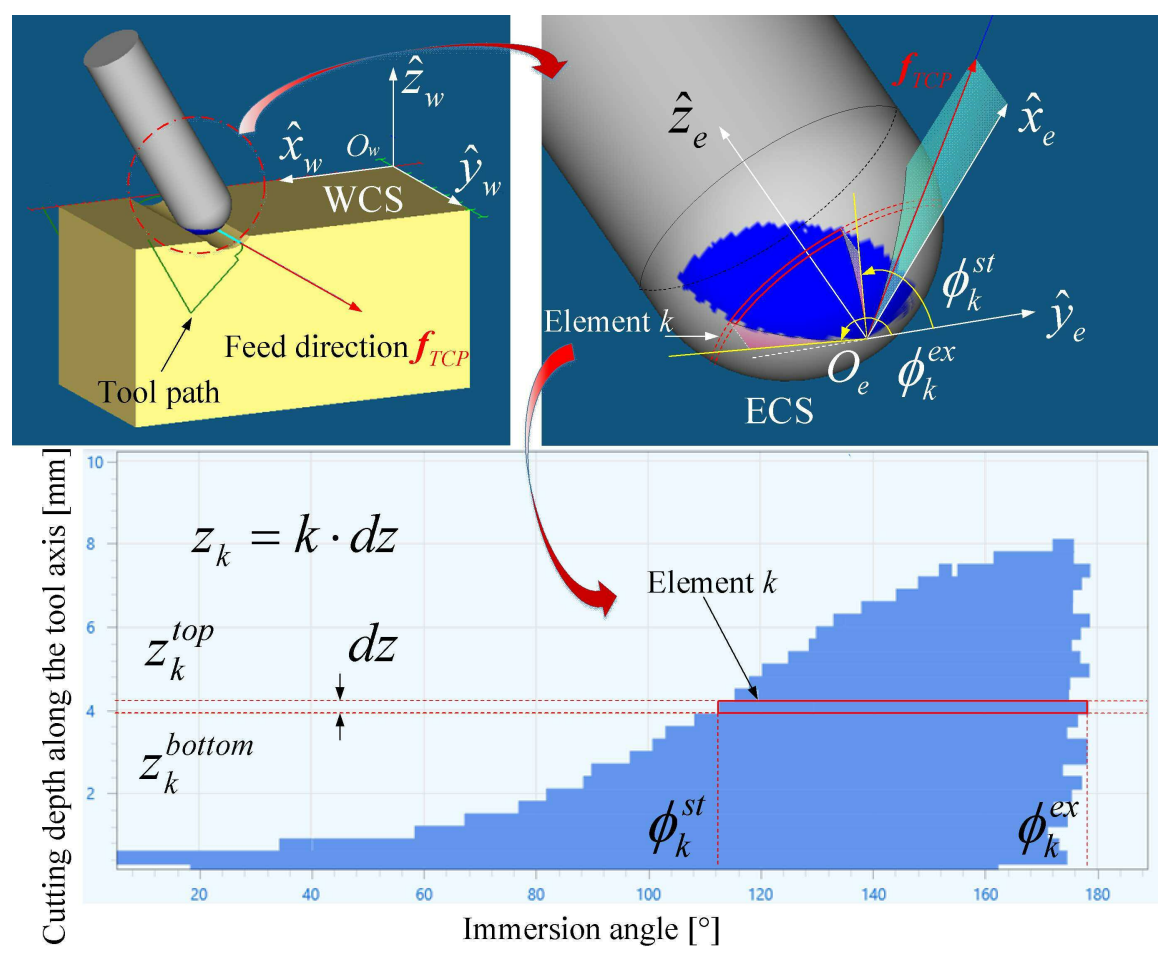

Figure 2 Tool-workpiece engagement on Work (WCS) and Engagement (ECS) coordinate systems.

The origin of ECS is fixed at the tool center point $O_{e}$ as shown in Figure 2. The position of $O_{e}$ in WCS is described in NC program, which can be denoted as $\{\mathbf{P}\}_{\text {wcs }}$ directly.

The $Z$ direction of ECS is aligned with the tool axis and its unit vector can be expressed in WCS as:

$$
\hat{z}_{e}=\left[\begin{array}{lll}
\hat{x}_{w} & \hat{y}_{w} & \hat{z}_{w}
\end{array}\right]\left\{\begin{array}{l}
o_{x} \\
o_{y} \\
o_{z}
\end{array}\right\}_{\mathrm{WCS}}=o_{x} \hat{x}_{w}+o_{y} \hat{y}_{w}+o_{z} \hat{z}_{w}
$$

where $\hat{x}_{w}, \hat{y}_{w}$ and $\hat{z}_{w}$ are the unit direction vectors of WCS, respectively (Figure 2). $o_{x}, o_{y}$ and $o_{z}$ are the elements of tool axis vector $\{\mathbf{O}\}_{\text {WCS }}$ obtained from the NC program.

The feed direction of tool center point in WCS can be evaluated from the positions of two adjacent tool locations as:

$$
\left\{\boldsymbol{f}_{\mathrm{TCP}}(i)\right\}_{\mathrm{wCS}}=\frac{\{\mathbf{P}(i+1)\}_{\mathrm{WCS}}-\{\mathbf{P}(i)\}_{\mathrm{wCS}}}{\left\|\{\mathbf{P}(i+1)\}_{\mathrm{wCS}}-\{\mathbf{P}(i)\}_{\mathrm{wCS}}\right\|}
$$

where $i=1,2,3 \ldots$ are the indexes of tool locations along the tool path.

The unit vector of $Y$ direction perpendicular to directions $\mathrm{Z}$ in ECS and feed motion in WCS is:

$$
\hat{y}_{e}=\frac{\hat{z}_{e} \times\left\{\boldsymbol{f}_{\mathrm{TCP}}(i)\right\}_{\mathrm{WCS}}}{\left\|\hat{z}_{e} \times\left\{\boldsymbol{f}_{\mathrm{TCP}}(i)\right\}_{\mathrm{WCS}}\right\|}=\left[\begin{array}{lll}
\hat{x}_{w} & \hat{y}_{w} & \hat{z}_{w}
\end{array}\right]\left\{\begin{array}{l}
v_{x} \\
v_{y} \\
v_{z}
\end{array}\right\}_{\mathrm{WCS}}=v_{x} \hat{x}_{w}+v_{y} \hat{y}_{w}+v_{z} \hat{z}_{w}
$$


Similarly, the unit vector of X direction in ECS can be expressed in WCS as:

$$
\hat{x}_{e}=\hat{y}_{e} \times \hat{z}_{e}=\left[\begin{array}{lll}
\hat{x}_{w} & \hat{y}_{w} & \hat{z}_{w}
\end{array}\right]\left\{\begin{array}{l}
u_{x} \\
u_{y} \\
u_{z}
\end{array}\right\}_{\mathrm{WCS}}=u_{x} \hat{x}_{w}+u_{y} \hat{y}_{w}+u_{z} \hat{z}_{w}
$$

The rotational transformation matrix $\left({ }^{n} \mathbf{R}_{e}\right.$ ) of ECS relative to WCS is defined as:

$$
{ }^{w} \mathbf{R}_{e}=\left[\begin{array}{ccc}
u_{x} & v_{x} & o_{x} \\
u_{y} & v_{y} & o_{y} \\
u_{z} & v_{z} & o_{z}
\end{array}\right]
$$

In summary, the orientation of three unit direction vectors $\hat{x}_{e}, \hat{y}_{e}$ and $\hat{z}_{e}$ of ECS are expressed in WCS as:

$$
\left[\begin{array}{lll}
\hat{x}_{e} & \hat{y}_{e} & \hat{z}_{e}
\end{array}\right]=\left[\begin{array}{lll}
\hat{x}_{w} & \hat{y}_{w} & \hat{z}_{w}
\end{array}\right]^{w} \mathbf{R}_{e}
$$

The rotational transformation matrix of TCS relative to ECS is:

$$
{ }^{e} \mathbf{R}_{t}={ }^{e} \mathbf{R}_{w} \cdot{ }^{w} \mathbf{R}_{t}={ }^{w} \mathbf{R}_{e}^{T} \cdot{ }^{w} \mathbf{R}_{t}
$$

\section{3) Transformation of tool and workpiece dynamics to ECS}

The regenerative tool $\left(\left\{\boldsymbol{\Delta}_{t}\right\}_{\mathrm{TCS}}\right)$ and workpiece $\left(\left\{\boldsymbol{\Delta}_{w}\right\}_{\mathrm{wCS}}\right)$ vibrations are defined in their coordinate systems in frequency domain as:

$$
\left\{\boldsymbol{\Delta}_{t}(i \omega)\right\}_{\mathrm{TCS}}=\boldsymbol{\Phi}_{t}(i \omega) \cdot\left\{\mathbf{F}_{t}(i \omega)\right\}_{\mathrm{TCS}} \quad ; \quad\left\{\boldsymbol{\Delta}_{w}(i \omega)\right\}_{\mathrm{WCS}}=\boldsymbol{\Phi}_{w}(i \omega) \cdot\left\{\mathbf{F}_{w}(i \omega)\right\}_{\mathrm{WCS}}
$$

where $\left(\boldsymbol{\Phi}_{t}(i \omega), \boldsymbol{\Phi}_{w}(i \omega)\right)$ are the FRF matrices of tool and workpiece structures, and $\left(\left\{\mathbf{F}_{t}(i \omega)\right\}_{\mathrm{TCS}},\left\{\mathbf{F}_{w}(i \omega)\right\}_{\mathrm{wCS}}\right)$ are the cutting force vectors acting on them, respectively.

First, the vibrations and cutting forces are transformed to WCS from their individual coordinate systems as follows:

$$
\left\{\boldsymbol{\Delta}_{t}\right\}_{\mathrm{WCS}}={ }^{w} \mathbf{R}_{t} \cdot\left\{\boldsymbol{\Delta}_{t}\right\}_{\mathrm{TCS}}
$$

where the complex frequency variable $(i \omega)$ is omitted to simplify the expressions.

The force on the tool in TCS is expressed as:

$$
\left\{\mathbf{F}_{t}\right\}_{\mathrm{TCS}}={ }^{t} \mathbf{R}_{w} \cdot\left\{\mathbf{F}_{t}\right\}_{\mathrm{WCS}} ;\left\{\mathbf{F}_{t}\right\}_{\mathrm{WCS}}={ }^{w} \mathbf{R}_{e} \cdot\left\{\mathbf{F}_{t}\right\}_{\mathrm{ECS}} \rightarrow\left\{\mathbf{F}_{t}\right\}_{\mathrm{TCS}}={ }^{t} \mathbf{R}_{w} \cdot{ }^{w} \mathbf{R}_{e} \cdot\left\{\mathbf{F}_{t}\right\}_{\mathrm{ECS}}
$$

The force on the workpiece in WCS is expressed as:

$$
\left\{\mathbf{F}_{w}\right\}_{\mathrm{WCS}}={ }^{w} \mathbf{R}_{e} \cdot\left\{\mathbf{F}_{w}\right\}_{\mathrm{ECS}}
$$

The forces on the workpiece and tool are the same but in the opposing directions:

$$
\left\{\mathbf{F}_{w}\right\}_{\text {wCS }}=-\left\{\mathbf{F}_{t}\right\}_{\text {wCS }}
$$

The relative vibration between the tool and workpiece can be evaluated in WCS as:

$$
\left\{\boldsymbol{\Delta}_{t w}\right\}_{\mathrm{WCS}}=\left\{\boldsymbol{\Delta}_{t}\right\}_{\mathrm{WCS}}-\left\{\boldsymbol{\Delta}_{w}\right\}_{\mathrm{WCS}}={ }^{w} \mathbf{R}_{t} \cdot\left\{\boldsymbol{\Delta}_{t}\right\}_{\mathrm{TCS}}-\left\{\boldsymbol{\Delta}_{w}\right\}_{\mathrm{WCS}}={ }^{w} \mathbf{R}_{t} \cdot \boldsymbol{\Phi}_{t} \cdot\left\{\mathbf{F}_{t}\right\}_{\mathrm{TCS}}-\boldsymbol{\Phi}_{w} \cdot\left\{\mathbf{F}_{w}\right\}_{\mathrm{WCS}}
$$

By substituting Eq.(15), (16) and (17) into Eq.(18), the relative vibration between tool and workpiece are transformed into ECS:

$$
\left\{\boldsymbol{\Delta}_{t w}\right\}_{\mathrm{ECS}}={ }^{e} \mathbf{R}_{w} \cdot\left\{\boldsymbol{\Delta}_{t w}\right\}_{\mathrm{WCS}}={ }^{e} \mathbf{R}_{w} \cdot\left({ }^{w} \mathbf{R}_{t} \cdot \boldsymbol{\Phi}_{t} \cdot{ }^{t} \mathbf{R}_{w}+\boldsymbol{\Phi}_{w}\right) \cdot{ }^{w} \mathbf{R}_{e}\left\{\mathbf{F}_{t}\right\}_{\mathrm{ECS}}
$$

The relative FRF between the tool and workpiece structures can be expressed in ECS as:

$$
\boldsymbol{\Phi}_{t w}={ }^{e} \mathbf{R}_{w} \cdot\left({ }^{w} \mathbf{R}_{t} \cdot \boldsymbol{\Phi}_{t} \cdot{ }^{t} \mathbf{R}_{w}+\boldsymbol{\Phi}_{w}\right) \cdot{ }^{w} \mathbf{R}_{e}={ }^{e} \mathbf{R}_{t} \cdot \boldsymbol{\Phi}_{t} \cdot{ }^{t} \mathbf{R}_{e}+{ }^{e} \mathbf{R}_{w} \cdot \boldsymbol{\Phi}_{w} \cdot{ }^{w} \mathbf{R}_{e}
$$


The relative vibrations between the tool and workpiece can be expressed as:

$$
\left\{\boldsymbol{\Delta}_{t w}\right\}_{\mathrm{ECS}}=\boldsymbol{\Phi}_{t w}\left\{\mathbf{F}_{t}\right\}_{\mathrm{ECS}}
$$

\section{3) Chatter stability in five-axis ball-end milling process}

\section{1) Cutting force model of ball-end mill}

The ball-end mill is composed of a spherical bottom and a cylindrical shank as shown in Figure 3.

(a)

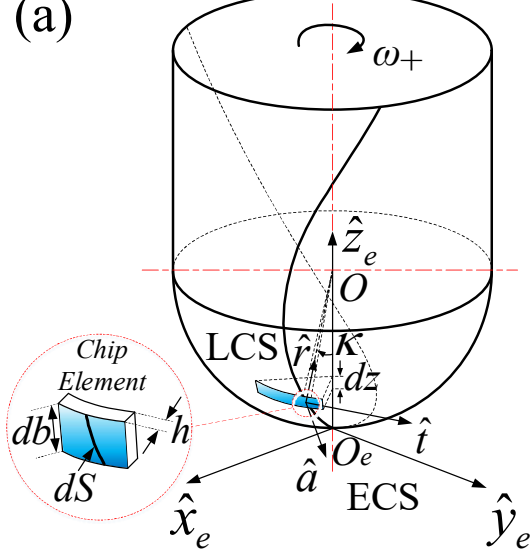

(b) $\quad \hat{y}_{e} \stackrel{\omega+}{\longleftarrow}$

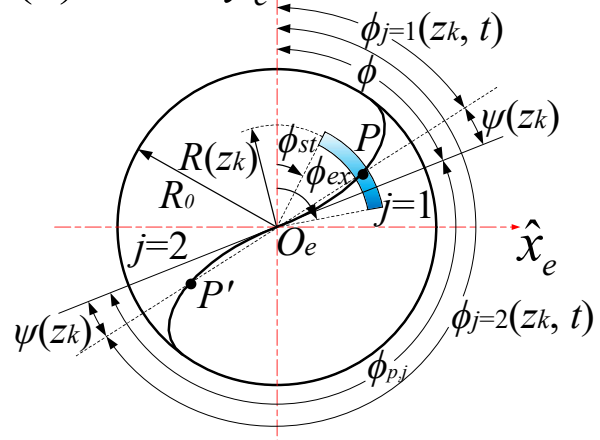

Figure 3 Envelope of ball-end mill. (a) Isometric view. (b) Top view.

The expression of the spherical ball-end mill with a nominal radius $R_{0}$ is $^{[24]}$ :

$$
x^{2}+y^{2}+\left(R_{0}-z\right)^{2}=R_{0}^{2}
$$

where $(x, y, z)$ are the coordinates of a point on the ball-end surface.

The elemental tangential, radial, and axial cutting forces $d F_{r,}{ }^{k}, d F_{t,}{ }^{k}, d F_{a, j}{ }_{j}$ contributed by the axial element $k$ on flute $j$ at time $t$ are expressed in local radial, tangential, and axial coordinate system (LCS) as:

$$
\left\{d \mathbf{F}_{\mathrm{LCS}, j}^{k}\left(z_{k}, t\right)\right\}=\left\{\begin{array}{l}
d F_{r, j}^{k}\left(z_{k}, t\right) \\
d F_{t, j}^{k}\left(z_{k}, t\right) \\
d F_{a, j}^{k}\left(z_{k}, t\right)
\end{array}\right\}=\left\{\left\{\begin{array}{l}
K_{r c} \\
K_{t c} \\
K_{a c}
\end{array}\right\} h_{j}\left(z_{k}, t\right) d b\left(z_{k}\right)+\left\{\begin{array}{l}
K_{r e} \\
K_{t e} \\
K_{a e}
\end{array}\right\} d S\left(z_{k}\right)\right\} g\left[\phi_{j}\left(z_{k}, t\right)\right]
$$

where $K_{r c}, K_{t c}, K_{a c}$ are cutting force coefficients contributed by the shearing in radial, tangential and axial directions, respectively; $K_{r e}, K_{t e}, K_{a e}$ are the edge force coefficients; $d b\left(z_{k}\right)$ is the width of the chip element; $d S\left(z_{k}\right)$ is the length of an infinitesimal curved cutting edge segment; $g\left[\phi_{j}\left(z_{k}, t\right)\right]$ is an angledependent binary parameter to consider if the edge is in or out of $\mathrm{cut}^{[25]} ; \phi_{j}\left(z_{k}, t\right)$ is the radial immersion angle of axial element $k$ on flute $j$ at time $t$; and $h_{j}\left(z_{k}, t\right)$ is the uncut chip thickness normal to the cutting edge of axial element $k$ on flute $j$ at time $t$ defined in the radial direction.

As shown in Figure $3(b)$, the bottom of first flute $(j=1)$ is regarded as the reference, and its rotation angle at time $t$ is $\phi(t)$ evaluated from the spindle speed $\Omega$ (rev/min):

$$
\phi(t)=\frac{2 \pi \Omega}{60} t
$$

The immersion angle of flute $j$ at axial elevation $z_{k}$ is expressed as: 


$$
\phi_{j}\left(z_{k}, t\right)=\phi(t)-\psi\left(z_{k}\right)+(j-1) \phi_{p}
$$

where $\phi_{p}=2 \pi / N_{t}$ is the pitch angle of tool with $N_{t}$ flutes; $\psi\left(z_{k}\right)$ is the lag angle which is defined for tools with constant lead and nominal helix angle $i_{0}$ as:

$$
\psi\left(z_{k}\right)=\frac{z_{k} \tan i_{0}}{R_{0}}
$$

The local cutter radius $R\left(z_{k}\right)$ and the local helix angle $i\left(z_{k}\right)$ are expressed as ${ }^{[26]}$ :

$$
\begin{aligned}
& R\left(z_{k}\right)=\left\{\begin{array}{cc}
\sqrt{R_{0}^{2}-\left(R_{0}-z_{k}\right)} & , z_{k} \leq R_{0} \\
R_{0} & , z_{k}>R_{0}
\end{array}\right. \\
& i\left(z_{k}\right)=\left\{\begin{array}{cc}
\arctan \left(\frac{R\left(z_{k}\right)}{R_{0}} \tan i_{0}\right) & , z_{k} \leq R_{0} \\
i_{0} & , z_{k}>R_{0}
\end{array}\right.
\end{aligned}
$$

For any point on a helical flute at elevation $z_{k}$, the local cutter radius $R\left(z_{k}\right)$ can be expressed as a function of the immersion angle as ${ }^{[24]}$ :

$$
R(\psi)=R_{0} \sqrt{1-\left(1-\psi \cot i_{0}\right)^{2}}
$$

The infinitesimal curved cutting edge segment $d S$ can be expressed as:

$$
d S(\psi)=\sqrt{[R(\psi)]^{2}+\left[R^{\prime}(\psi)\right]^{2}+\left(R_{0} \cot i\right)^{2}} d \psi
$$

where the derivative of $R(\psi)$ is:

$$
R^{\prime}(\psi)=\frac{-R_{0}\left(\psi \cot i_{0}-1\right) \cot i_{0}}{\sqrt{1-\left(\psi \cot i_{0}-1\right)^{2}}}
$$

The width of the chip element $d b\left(z_{k}\right)$ depends on the axial immersion angle of element $k$ on flute $j$, i.e. $\kappa\left(z_{k}\right)$ :

$$
d b\left(z_{k}\right)=\frac{d z}{\sin \kappa\left(z_{k}\right)}
$$

where $\kappa\left(z_{k}\right)$ is evaluated by:

$$
\kappa\left(z_{k}\right)=\arcsin \left(\frac{R\left(z_{k}\right)}{R_{0}}\right)
$$

The binary parameter $g\left[\phi_{j}\left(z_{k}, t\right)\right]$ is used to determine whether the axial element $k$ on flute $j$ is in cut or not as:

$$
g\left[\phi_{j}\left(z_{k}, t\right)\right]=\left\{\begin{array}{cc}
1, & \phi_{s t, j} \leq \phi_{j}\left(z_{k}, t\right) \leq \phi_{e x, j} \\
0, & \text { otherwise }
\end{array}\right.
$$


The chip thickness $h_{j}\left(z_{k}, t\right)$ consists of the static component caused by the rigid body motions between tool and workpiece, and the dynamic component $h_{d, j}\left(z_{k}, t\right)$ which is contributed by the relative vibrations between the tool and workpiece:

$$
h_{j}\left(z_{k}, t\right)=h_{s, j}\left(z_{k}, t\right)+h_{d, j}\left(z_{k}, t\right)
$$

where the dynamic chip thickness component $h_{d, j}\left(z_{k}, t\right)$ is derived from two successive surfaces left by flutes $j-1$ and $j$ :

$$
h_{d, j}\left(z_{k}, t\right)=r_{e,(j-1)}\left(z_{k}, t-T_{t}\right)-r_{e, j}\left(z_{k}, t\right)
$$

where $r_{e,(j-1)}\left(z_{k}, t-T_{t}\right)$ and $r_{e, j}\left(z_{k}, t\right)$ are the dynamic displacements of the flute at the previous $(j-$ $1)$ and present $(j)$ tooth periods, respectively. The tooth passing period for a uniform pitch cutter is $T_{t}=2 \pi /\left(\Omega N_{t}\right)$, but it can be replaced by $T_{j}$ for variable pitch tools.

Assuming that the structure can vibrate in three directions, the dynamic chip thickness component can be expressed in ECS as:

$$
\begin{aligned}
h_{d, j}\left(z_{k}, t\right)=[ & \Delta x\left(z_{k}, t\right) \sin \kappa\left(z_{k}\right) \sin \phi_{j}\left(z_{k}, t\right) \\
+ & \Delta y\left(z_{k}, t\right) \sin \kappa\left(z_{k}\right) \cos \phi_{j}\left(z_{k}, t\right) \\
& \left.-\Delta z\left(z_{k}, t\right) \cos \kappa\left(z_{k}\right)\right]
\end{aligned}
$$

where the relative displacement in $\mathrm{X}$ direction can be derived by:

$$
\Delta x\left(z_{k}, t\right)=\left[x_{j, T}\left(z_{k}, t\right)-x_{j, W}\left(z_{k}, t\right)\right]-\left[x_{(j-1), T}\left(z_{k}, t-T_{t}\right)-x_{(j-1), W}\left(z_{k}, t-T_{t}\right)\right]
$$

Here, $x_{j, T}\left(z_{k}, t\right)$ and $x_{(j-1), T}\left(z_{k}, t-T_{t}\right)$ represent the dynamic displacements of tool in $\mathrm{X}$ direction of ECS at the present and previous tooth periods, respectively. Similarly, $x_{j, W}\left(z_{k}, t\right)$ and $x_{(j-1), W}\left(z_{k}, t-T_{t}\right)$ represent the dynamic displacements of workpiece in $\mathrm{X}$ direction. The definition of $\Delta y\left(z_{k}, t\right)$ and $\Delta z\left(z_{k}, t\right)$ are analogous to $\Delta x\left(z_{k}, t\right)$.

The elemental cutting force defined in cutting edge local coordinate system (LCS) is transformed to ECS by introducing the rotational matrix ${ }^{e} \mathbf{R}_{l}$.

$$
\{\mathbf{F}\}_{\mathrm{ECS}}={ }^{e} \mathbf{R}_{l}\{\mathbf{F}\}_{\mathrm{LCS}} \leftarrow{ }^{e} \mathbf{R}_{l}=\left[\begin{array}{ccc}
-\sin \kappa\left(z_{k}\right) \sin \phi_{j}\left(z_{k}, t\right) & -\cos \phi_{j}\left(z_{k}, t\right) & -\cos \kappa\left(z_{k}\right) \sin \phi_{j}\left(z_{k}, t\right) \\
-\sin \kappa\left(z_{k}\right) \cos \phi_{j}\left(z_{k}, t\right) & \sin \phi_{j}\left(z_{k}, t\right) & -\cos \kappa\left(z_{k}\right) \cos \phi_{j}\left(z_{k}, t\right) \\
\cos \kappa\left(z_{k}\right) & 0 & -\sin \kappa\left(z_{k}\right)
\end{array}\right]
$$

\section{2) Chatter stability analysis}

Since the static chip thickness does not contribute to the dynamic chip load regeneration mechanism ${ }^{[3]}$, it is dropped from the Eq. (23) as:

$$
\left\{d \mathbf{F}_{\mathrm{LCS}, d, j}^{k}\left(z_{k}, t\right)\right\}=\left\{\begin{array}{l}
d F_{r, d, j}^{k}\left(z_{k}, t\right) \\
d F_{t, d, j}^{k}\left(z_{k}, t\right) \\
d F_{a, d, j}^{k}\left(z_{k}, t\right)
\end{array}\right\}=\left\{\begin{array}{l}
K_{r c} \\
K_{t c} \\
K_{a c}
\end{array}\right\} h_{d, j}\left(z_{k}, t\right) d b\left(z_{k}\right) g\left[\phi_{j}\left(z_{k}, t\right)\right]
$$

Substituting Eq.(32) and Eq. (37) into (40) yields:

$$
\left\{d \mathbf{F}_{\mathrm{LCS}, d, j}^{k}\left(z_{k}, t\right)\right\}=\left\{\mathbf{K}_{r t a}^{c}\right\}\left\{\mathbf{n}_{j}\left(z_{k}, t\right)\right\}^{T}\left\{\boldsymbol{\Delta}_{j}\left(z_{k}, t\right)\right\} \frac{d z}{\sin \kappa\left(z_{k}\right)} \cdot g\left[\phi_{j}\left(z_{k}, t\right)\right]
$$


The cutting forces are transformed from LCS to ECS by the rotational matrix defined in Eq. (39) :

$$
\begin{aligned}
& \left\{d \mathbf{F}_{\mathrm{ECS}, d, j}^{k}\left(z_{k}, t\right)\right\}={ }^{e} \mathbf{R}_{l} \cdot\left\{d \mathbf{F}_{\mathrm{LCS}, d, j}^{k}\left(z_{k}, t\right)\right\}=\mathbf{A}_{j}\left(z_{k}, t\right)\left\{\boldsymbol{\Delta}_{j}\left(z_{k}, t\right)\right\} \\
& \mathbf{A}_{j}\left(z_{k}, t\right)={ }^{e} \mathbf{R}_{l}\left\{\mathbf{K}_{r t a}^{c}\right\}\left\{\mathbf{n}_{j}\left(z_{k}, t\right)\right\}^{T} \frac{d z}{\sin \kappa\left(z_{k}\right)} \cdot g\left[\phi_{j}\left(z_{k}, t\right)\right]
\end{aligned}
$$

where $\mathbf{A}_{j}\left(z_{k}, t\right)$ are directional coefficient matrices for a single tool-workpiece engagement which are periodic at the tooth passing frequency $\omega_{T}=2 \pi / T_{t}$. The Fourier expansion of periodic coefficient matrices is:

$$
\mathbf{A}_{j}\left(z_{k}, t\right)=\sum_{r=-\infty}^{\infty} \mathbf{A}_{j, k, r} e^{i r \omega_{T} t} \leftarrow \mathbf{A}_{j, k, r}=\frac{1}{T_{t}} \int_{0}^{T_{t}} \mathbf{A}_{j}\left(z_{k}, t\right) e^{-i r \omega_{T} t} d t
$$

As shown in $[8,12,13]$, for chatter stability analysis, the zero-order form (i.e. $r=0$ ) is feasible by considering only the average of the periodic coefficients as:

$$
\mathbf{A}_{j}\left(z_{k}, t\right) \approx \mathbf{A}_{j, k, 0}=\frac{1}{T_{t}} \int_{0}^{T_{t}} \mathbf{A}_{j}\left(z_{k}, t\right) d t=\frac{1}{\phi_{p}} \int_{0}^{\phi_{p}} \mathbf{A}_{j}\left(z_{k}, t\right) d \phi_{j}
$$

The relative vibrations in Eq. (42) are evaluated by the present vibration and the vibration of previous tooth passing period between the tool and workpiece:

$$
\left\{\boldsymbol{\Delta}_{j}\left(z_{k}, t\right)\right\}=\left\{\begin{array}{l}
\Delta x_{j}\left(z_{k}, t\right) \\
\Delta y_{j}\left(z_{k}, t\right) \\
\Delta z_{j}\left(z_{k}, t\right)
\end{array}\right\}=\left\{\begin{array}{l}
x_{j, T}\left(z_{k}, t\right)-x_{(j-1), T}\left(z_{k}, t-\tau\right) \\
y_{j, T}\left(z_{k}, t\right)-y_{(j-1), T}\left(z_{k}, t-\tau\right) \\
z_{j, T}\left(z_{k}, t\right)-z_{(j-1), T}\left(z_{k}, t-\tau\right)
\end{array}\right\}-\left\{\begin{array}{l}
x_{j, W}\left(z_{k}, t\right)-x_{(j-1), W}\left(z_{k}, t-\tau\right) \\
y_{j, W}\left(z_{k}, t\right)-y_{(j-1), W}\left(z_{k}, t-\tau\right) \\
z_{j, W}\left(z_{k}, t\right)-z_{(j-1), W}\left(z_{k}, t-\tau\right)
\end{array}\right\}
$$

Eq. (45) can be transformed into Laplace domain as:

$$
\boldsymbol{\Delta}_{j}\left(z_{k}, s\right)=\left(1-e^{-s T_{t}}\right)\left(\left\{\begin{array}{l}
x_{j, T}\left(z_{k}, s\right) \\
y_{j, T}\left(z_{k}, s\right) \\
z_{j, T}\left(z_{k}, s\right)
\end{array}\right\}-\left\{\begin{array}{l}
x_{j, W}\left(z_{k}, s\right) \\
y_{j, W}\left(z_{k}, s\right) \\
z_{j, W}\left(z_{k}, s\right)
\end{array}\right\}\right)
$$

which can be expressed as a function of structural FRFs (Eq. (20)) and dynamic cutting forces as:

$$
\left\{\boldsymbol{\Delta}_{j}\left(z_{k}, s\right)\right\}=\left(1-e^{-s T_{t}}\right) \boldsymbol{\Phi}_{t w}\left\{d \mathbf{F}_{\mathrm{ECS}, j}^{k}\left(z_{k}, s\right)\right\}
$$

By substituting Eq. (47) into Eq. (42) and rearranging it gives:

$$
\left(\mathbf{I}-\mathbf{A}_{j, k, 0}\left(1-e^{-s T_{t}}\right) \boldsymbol{\Phi}_{t w}\right)\left\{d \mathbf{F}_{\mathrm{ECS}, j}^{k}\left(z_{k}, s\right)\right\}=\{\mathbf{0}\}
$$

where $\mathbf{I}$ is a $3 \times 3$ identity matrix.

The total cutting dynamics of the ball-end milling system can be obtained by summing the contributions of all axial elements of the flutes that are within the TWE as:

$$
\left(\mathbf{I}-\sum_{k=1}^{N_{z}} \sum_{j=1}^{N_{t}} \mathbf{A}_{j, k, 0}\left(1-e^{-s T_{t}}\right) \boldsymbol{\Phi}_{t w}\right)\left\{\mathbf{F}_{\mathrm{ECS}}(s)\right\}=\{\mathbf{0}\}
$$

By setting $s=j \omega_{c}$ for the critical stability condition, the characteristic equation of the dynamic cutting system in frequency domain becomes:

$$
\operatorname{det}\left|\mathbf{I}-\sum_{k=1}^{N_{z}} \sum_{j=1}^{N_{t}} \mathbf{A}_{j, k, 0}\left(1-e^{-j \omega_{c} T_{t}}\right) \mathbf{\Phi}_{t w}\right|=0
$$

By varying the frequency $\omega_{c}$ at the measured ranges of FRF, the stability of the cutting process can be evaluated at each tool location along the tool path using Nyquist criterion ${ }^{[27]}$. 


\section{4) Forced vibration in five-axis milling process}

Once the process is stabilized by selecting speeds and engagement conditions, the regenerative dynamic chip thickness component can be dropped $\left(h_{d, j}\left(z_{k}, t\right)=0\right)$ while keeping its static component $h_{s, j}\left(z_{k}, t\right)$ in Eq.(35) to predict the forced vibrations.

In five-axis machining, the feed speed varies along the tool axis caused by the tilting of tool. The total feed speed at a given axial height $z_{k}$ on the tool can be decomposed into a linear feed component $\left(\boldsymbol{f}_{L}(i)\right)$ at the tool center point as described by Eq. (7), and an angular feed component $\left(\boldsymbol{f}_{A}\left(z_{k}, i\right)\right)$ at the height $z_{k}^{[28]}$.

$$
\boldsymbol{f}_{T}\left(z_{k}, i\right)=\boldsymbol{f}_{L}(i)+\boldsymbol{f}_{A}\left(z_{k}, i\right)
$$

By assuming that the TWE remains unchanged within two consecutive locations $((i)$ and $(i+1))$ along a short tool path interval, the linear feed component can be expressed in ECS as:

$$
\boldsymbol{f}_{L}(i)=f(i) \cdot{ }^{e} \mathbf{R}_{w} \cdot\left\{\boldsymbol{f}_{\mathrm{TCP}}(i)\right\}_{\mathrm{WCS}}
$$

where $f(i)$ is the nominal feed rate at tool location point $(i)$ read from NC program.

In the short tool path interval, assume that the tool axis rotate an angle $\Delta \theta_{f}(i)$ at a constant angular speed $\omega_{f}(i)$ around the tool center point in the elapsed time interval $\Delta t_{f}(i)$ :

$$
\Delta \theta_{f}(i)=\arctan \frac{\|\mathbf{O}(i) \times \mathbf{O}(i+1)\|}{\mathbf{O}(i) \cdot \mathbf{O}(i+1)} ; \Delta t_{f}(i)=\frac{\|\mathbf{P}(i+1)-\mathbf{P}(i)\|}{f(i)} ; \omega_{f}(i)=\frac{\Delta \theta_{f}(i)}{\Delta t_{f}(i)}
$$

The unit vector of the rotational axis passing through the tool center point can be defined by the tool axis vectors of these two consecutive locations:

$$
\mathbf{q}_{f}(i)=\frac{\mathbf{O}(i) \times \mathbf{O}(i+1)}{\|\mathbf{O}(i) \times \mathbf{O}(i+1)\|}
$$

The angular feed along the tool axis is expressed as:

$$
\boldsymbol{f}_{A}\left(z_{k}, i\right)=\omega_{f}(i) \cdot{ }^{e} \mathbf{R}_{w} \cdot \mathbf{q}_{f}(i) \times z_{k} \cdot{ }^{e} \mathbf{R}_{w} \cdot \mathbf{O}(i)=\omega_{f}(i) \cdot{ }^{e} \mathbf{R}_{w} \cdot \mathbf{q}_{f}(i) \times z_{k} \cdot\left[\begin{array}{l}
0 \\
0 \\
1
\end{array}\right]
$$

The static component of chip thickness $h_{s, j}\left(z_{k}, t\right)$ in Eq. (35) can be evaluated by projecting the total feed speed onto the normal direction of ball-end mill at height $z_{k}$ :

$$
h_{s, j}\left(z_{k}, t\right)=\frac{60}{\Omega N_{t}}\left\{\mathbf{n}_{j}\left(z_{k}, t\right)\right\}^{T} \cdot \boldsymbol{f}_{T}\left(z_{k}, i\right)
$$

Then, the chatter-free cutting forces can be evaluated by Eq.(23) where the dynamic component of chip thickness $h_{d, j}\left(z_{k}, t\right)$ is dropped.

The forced vibrations in ECS can be derived by taking the inverse Fourier transformation of the vibrations computed in the frequency domain as:

$$
\{\boldsymbol{x}(t)\}=\mathcal{F}^{-1}\{\mathbf{X}(j \omega)\}=\mathcal{F}^{-1}\{\boldsymbol{\Phi}(j \omega) \cdot \mathbf{F}(j \omega)\}
$$

where $\{\boldsymbol{x}(t)\}_{3 \times 1}$ is a time dependent displacement in three directions.

The vibrations on the workpiece (WCS) and tool (TCS) can be obtained by transforming Eq. (57) using corresponding rotational transformations. 
Alternatively, the cutting forces can be computed more efficiently in the frequency domain using the products of harmonics of the forces with the FRFs as proposed by Yang et al. ${ }^{[29]}$.

The overall calculation scheme for the chatter stability and forced vibration estimations of five-axis ball-end milling process is summarized in Figure 4.

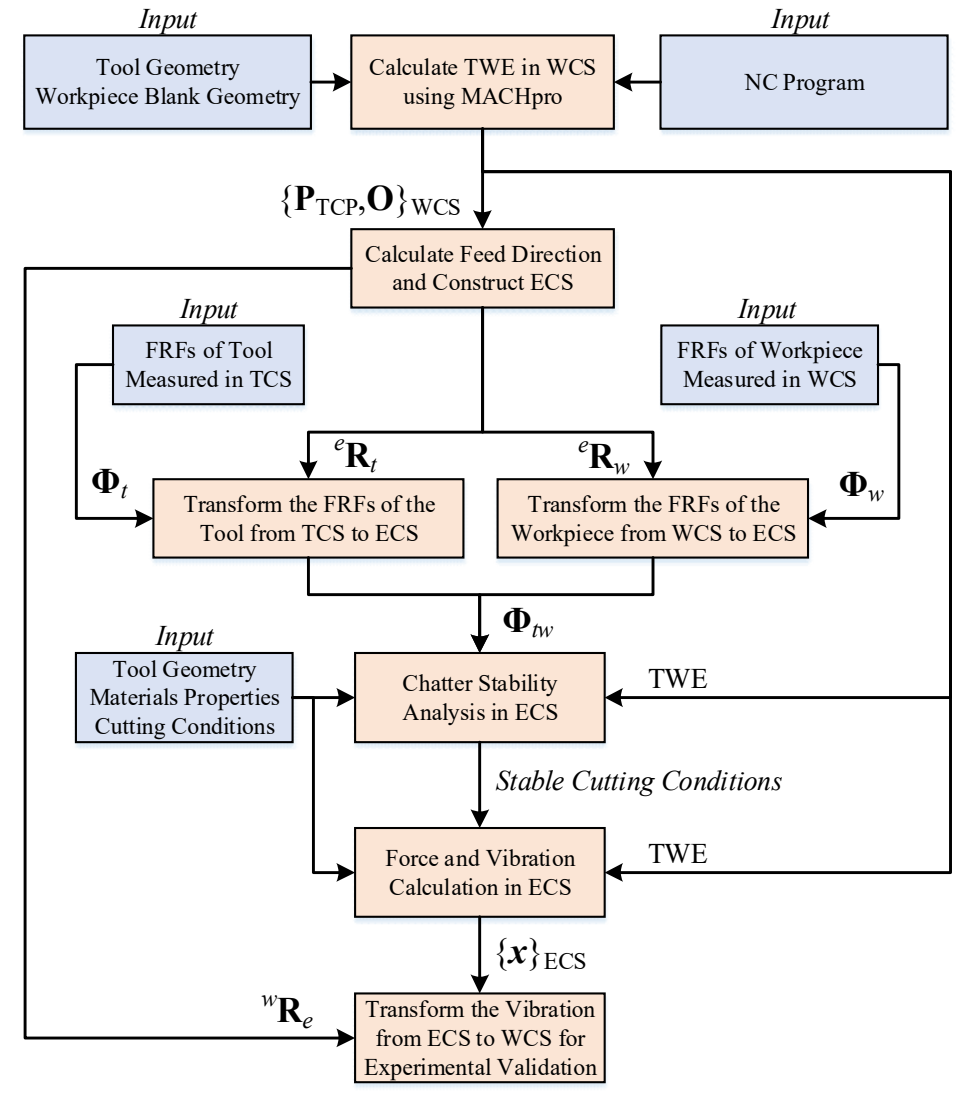

Figure 4 Flow chart for the chatter stability and forced vibration estimations of five-axis ball-end milling process.

\section{5) Simulation and experimental results}

The proposed model has been experimentally validated along six straight tool paths with various tool axis orientations listed in Table 1. The workpiece is very flexible, thin-walled plate as shown in Figure 5.

Table 1 Angles of two rotary axes and tool axis vectors for different tool orientations.

\begin{tabular}{|c|c|c|c|}
\hline Tool path & \multicolumn{2}{|c|}{ Rotational angle } & Tool Axis in WCS \\
\hline & A & $\mathrm{C}$ & $o_{x}$ \\
\hline 1 & $-30^{\circ}$ & $30^{\circ}$ & $-0.250,0.433,0.866$ \\
\hline 2 & $-30^{\circ}$ & $60^{\circ}$ & $-0.433,0.250,0.866$ \\
\hline 3 & $-30^{\circ}$ & $90^{\circ}$ & $-0.500,0.000,0.866$ \\
\hline 4 & $-60^{\circ}$ & $30^{\circ}$ & $-0.433,0.750,0.500$ \\
\hline 5 & $-60^{\circ}$ & $60^{\circ}$ & $-0.750,0.433,0.500$ \\
\hline 6 & $-60^{\circ}$ & $90^{\circ}$ & $-0.866,0.000,0.500$ \\
\hline
\end{tabular}




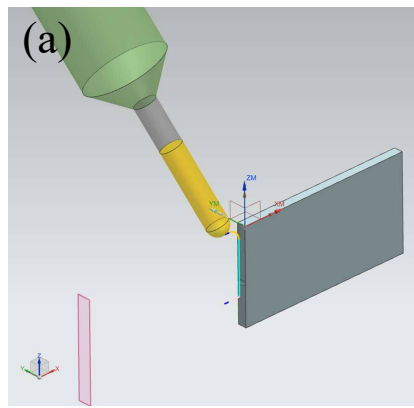

(d)

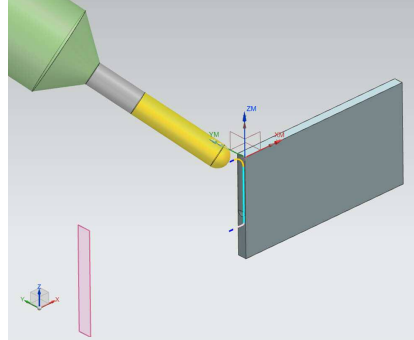

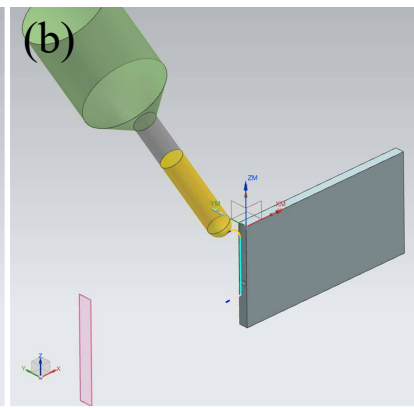

(e)

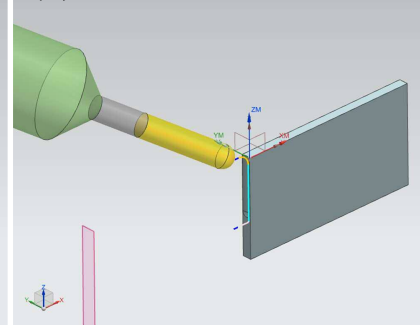

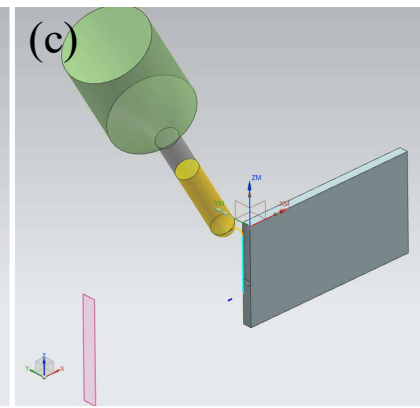

(f)

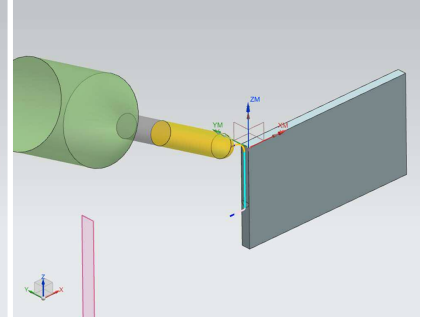

Figure 5 The orientation of the tool related to the workpiece with different $\mathrm{A} / \mathrm{C}$ angles. (a) $\mathrm{A}=-30^{\circ}, \mathrm{C}=30^{\circ}$. (b) $\mathrm{A}=-30^{\circ}, \mathrm{C}=60^{\circ}$. (c) $\mathrm{A}=-30^{\circ}, \mathrm{C}=90^{\circ}$. (d) $\mathrm{A}=-60^{\circ}, \mathrm{C}=30^{\circ}$. (e) $\mathrm{A}=-60^{\circ}, \mathrm{C}=60^{\circ}$. (f) $\mathrm{A}=-60^{\circ}, \mathrm{C}=90^{\circ}$.

The ball-end mill is flexible in X and Y directions, its measured FRFs in TCS are given in Figure 6, and modal parameters are summarized in Table 2.
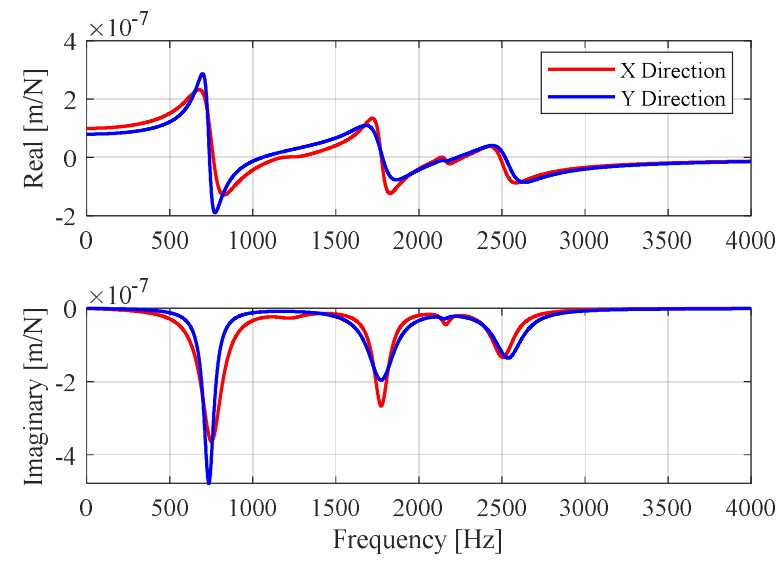

Figure 6 FRFs of the tool measured in TCS.

Table 2 Modal parameters of tool in TCS.

\begin{tabular}{ccccc}
\hline Direction & Mode & $f_{n}[\mathrm{~Hz}]$ & $\zeta_{m}[\%]$ & $k_{m}[\mathrm{~N} / \mathrm{m}]$ \\
\hline $\mathrm{X}$ & 1 & 754 & 9.93 & $1.3959 \times 10^{7}$ \\
& 2 & 1773 & 3.03 & $6.2761 \times 10^{7}$ \\
& 3 & 2506 & 2.62 & $1.1490 \times 10^{8}$ \\
$\mathrm{Y}$ & 1 & 736 & 5.08 & $2.0670 \times 10^{7}$ \\
& 2 & 1775 & 5.33 & $4.8542 \times 10^{7}$ \\
& 3 & 2539 & 4.03 & $9.3387 \times 10^{7}$ \\
\hline
\end{tabular}

Eight cantilevered thin-walled plates (Figure 7) machined from Aluminum 7050-T7451 with the same dimensions $(135 \mathrm{~mm} \times 54 \mathrm{~mm} \times 5 \mathrm{~mm})$ were used for the chatter stability verification. 


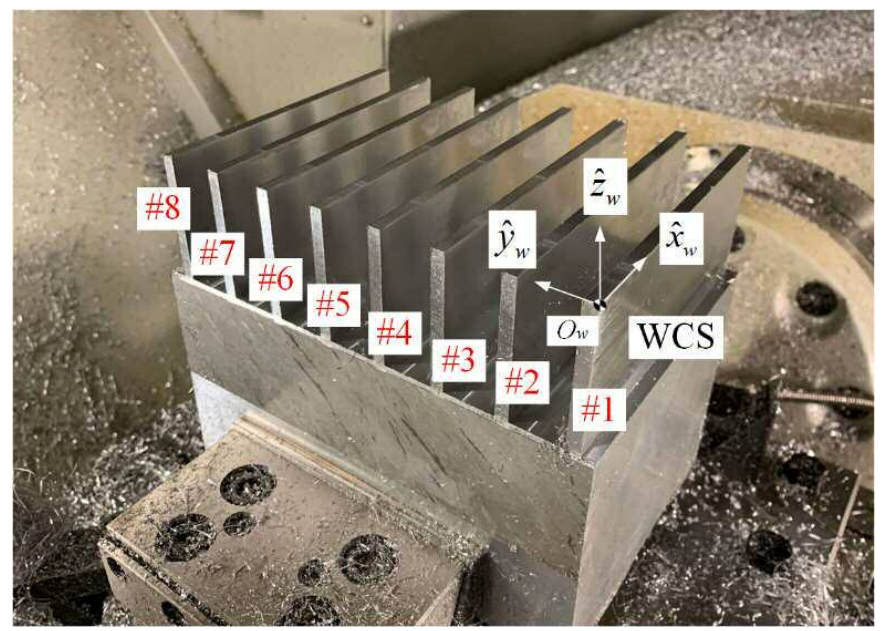

Figure 7 Workpiece for experiment.

The measured FRFs of each thin-walled plate at the origin of the WCS are almost the same, and their modal parameters are given in Table 3. The workpiece is much more flexible than the tool.

Table 3 Modal parameters of cantilevered plates in $\hat{y}_{w}$ direction at the origin of WCS shown in Figure 7.

\begin{tabular}{cccc}
\hline Mode & $f_{n}[\mathrm{~Hz}]$ & $\zeta_{m}[\%]$ & $k_{m}[\mathrm{~N} / \mathrm{m}]$ \\
\hline 1 & 1336 & 0.17 & $1.5 \times 10^{6}$ \\
2 & 1798 & 0.60 & $1.2 \times 10^{6}$ \\
3 & 3141 & 1.68 & $3.0 \times 10^{6}$ \\
\hline
\end{tabular}

A 2 flutes ball-end mill with $12 \mathrm{~mm}$ diameter and $30^{\circ}$ helix angle was used in the tests. The feed rate was kept constant at $0.1 \mathrm{~mm} / \mathrm{tooth} / \mathrm{rev}$ and the distance from the center of the tool's ball part to the uncut surface of the workpiece was $5.5 \mathrm{~mm}$ in all cutting paths. The cutting force coefficients are extracted for Al 7050-T7451 from CutPro ${ }^{\mathrm{TM}}$ database $^{[30]}$ as: $K_{r c}=178 \mathrm{~N} / \mathrm{mm}^{2} ; K_{t c}=752 \mathrm{~N} / \mathrm{mm}^{2} ; K_{a c}=100 \mathrm{~N} / \mathrm{mm}^{2} ; K_{r e}=30$ $\mathrm{N} / \mathrm{mm} ; K_{t e}=20 \mathrm{~N} / \mathrm{mm} ; K_{a e}=0.1 \mathrm{~N} / \mathrm{mm}$.

The cutting stability of each tool location along the tool path is checked from Eq. (50) using the Nyquist Criterion. Although the radial and axial depths of cut remain the same, the distribution of the engagements varies as a function of tool orientation as shown in Figure 8. Since the distribution of engagements is different, the directional factors hence the stability in ECS will also be different for different tool orientations as the predicted results indicate in Figure 9. 

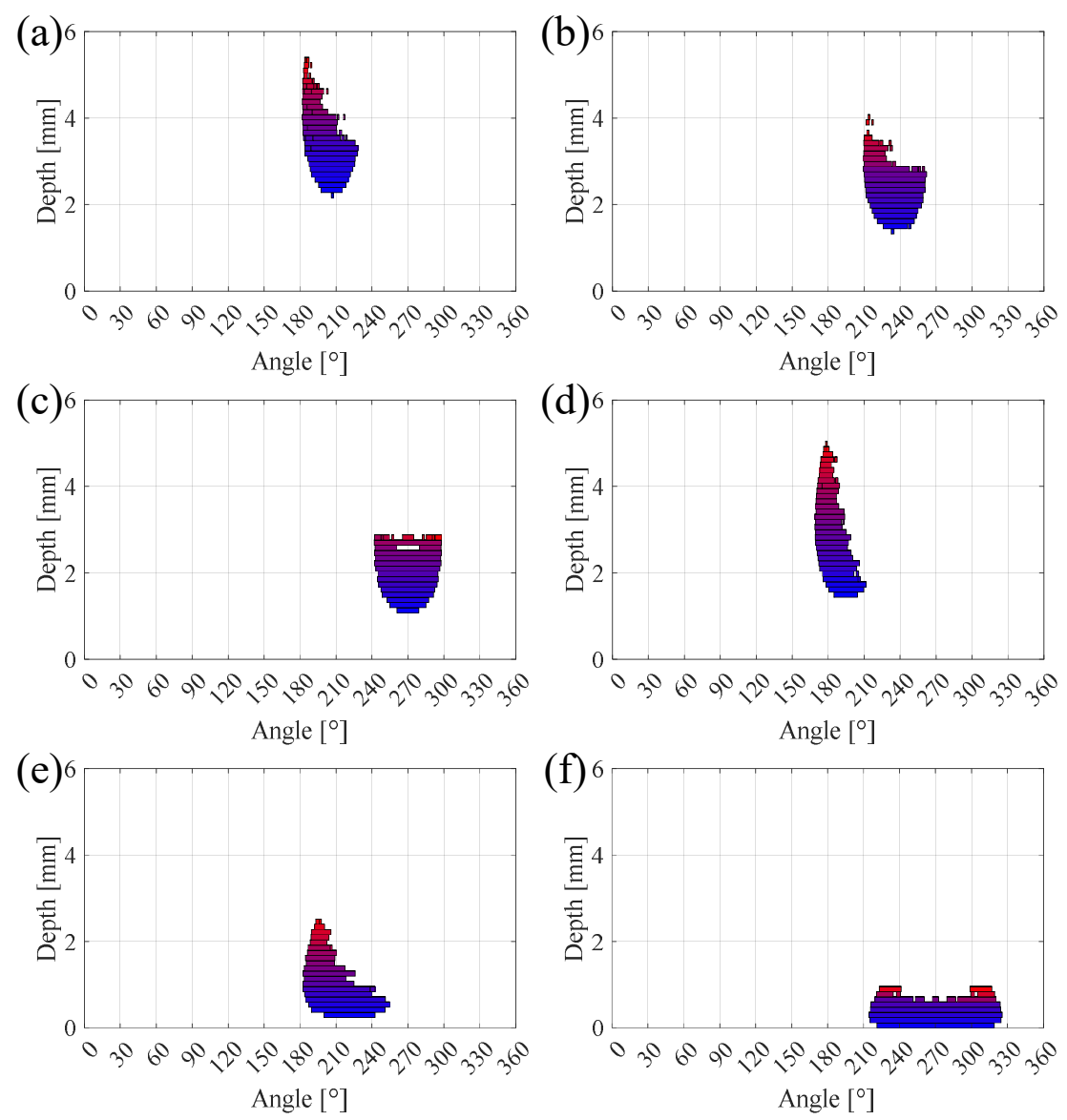

Figure 8 Tool-workpiece engagements for the tool paths with different $A / C$ angles. (a) $A=-30^{\circ}, C=30^{\circ}$. (b) $A=-30^{\circ}, C=60^{\circ}$. (c) $\mathrm{A}=-30^{\circ}, \mathrm{C}=90^{\circ}$. (d) $\mathrm{A}=-60^{\circ}, \mathrm{C}=30^{\circ}$. (e) $\mathrm{A}=-60^{\circ}, \mathrm{C}=60^{\circ}$. (f) $\mathrm{A}=-60^{\circ}, \mathrm{C}=90^{\circ}$. 
(a)

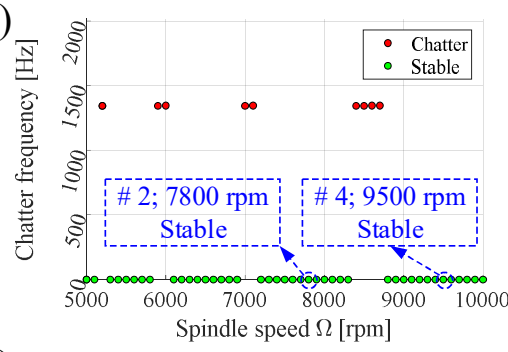

(c)

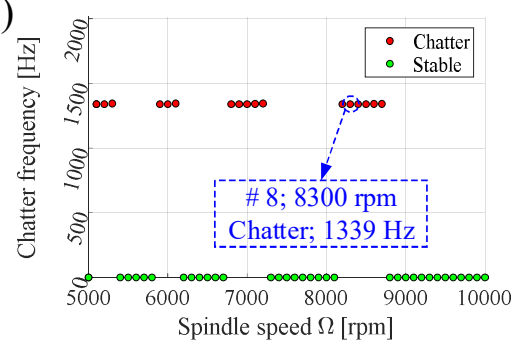

(e)

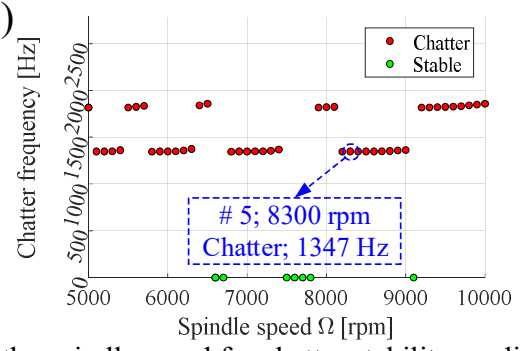

(b)

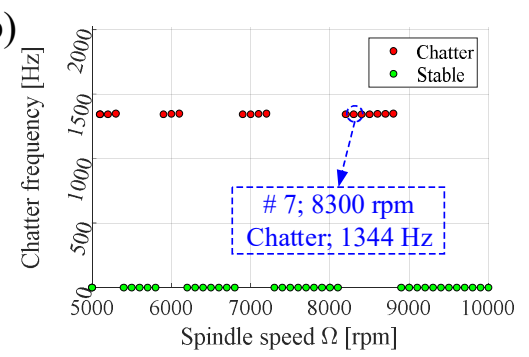

(d)

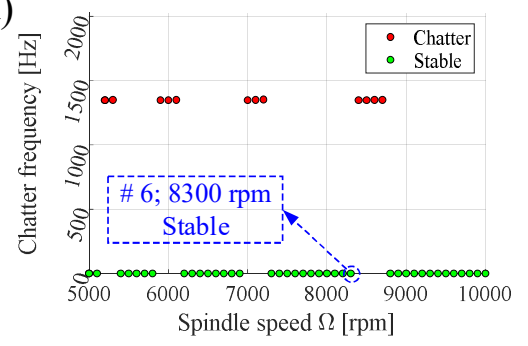

(f)

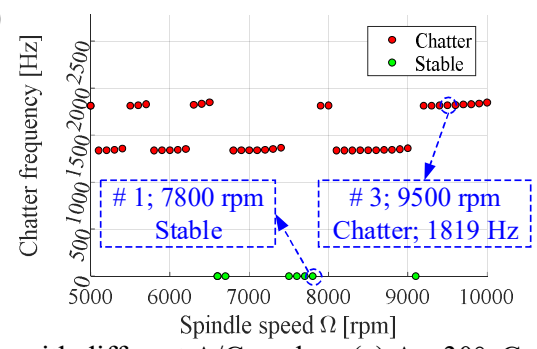

Figure 9 Sweeping the spindle speed for chatter stability prediction with different $A / C$ angles. (a) $A=-30^{\circ}$, $C=3$
\[ C=60^{\circ} \text {. (c) } A=-30^{\circ}, C=90^{\circ} \text {. (d) } A=-60^{\circ}, C=30^{\circ} \text {. (e) } A=-60^{\circ}, C=60^{\circ} \text {. (f) } A=-60^{\circ}, C=90^{\circ} \text {. } \]

The cutting parameters for each thin-walled plate machining test are listed in Table 4 with the corresponding machined surface photographs given in Figure 10.

Table 4 Cutting parameters for 8 thin-walled Al6061 plates. Tool: A 2 fluted ball-end mill with $12 \mathrm{~mm}$ diameter and $30^{\circ}$ helix angle. Workpiece: Al 7050-T7451.

\begin{tabular}{ccccc}
\hline Plate No. & $\mathrm{A}\left[{ }^{\circ}\right]$ & $\mathrm{C}\left[{ }^{\circ}\right]$ & $\Omega[\mathrm{rpm}]$ & $f[\mathrm{~mm} / \mathrm{min}]$ \\
\hline$\# 1$ & -60 & 90 & 7800 & 1560 \\
$\# 2$ & -30 & 30 & 7800 & 1560 \\
$\# 3$ & -60 & 90 & 9500 & 1900 \\
$\# 4$ & -30 & 30 & 9500 & 1900 \\
$\# 5$ & -60 & 60 & 8300 & 1660 \\
$\# 6$ & -60 & 30 & 8300 & 1660 \\
$\# 7$ & -30 & 60 & 8300 & 1660 \\
$\# 8$ & -30 & 90 & 8300 & 1660 \\
\hline
\end{tabular}



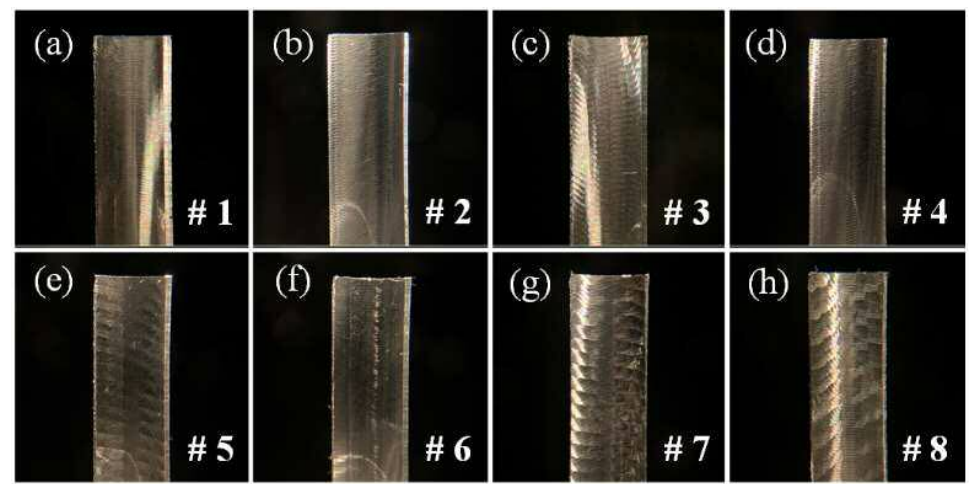

Figure 10 The machined surfaces of the 8 thin-walled plates.

(a) \#1. (b) \#2. (c) \#3. (d) \#4. (e) \#5. (f) \#6. (g) \#7. (h) \#8.

The power spectrum of measured cutting forces in the Y direction of WCS are shown in Figure 11, there the gray dashed lines in each diagram indicate the spindle rotation frequency and its harmonics.
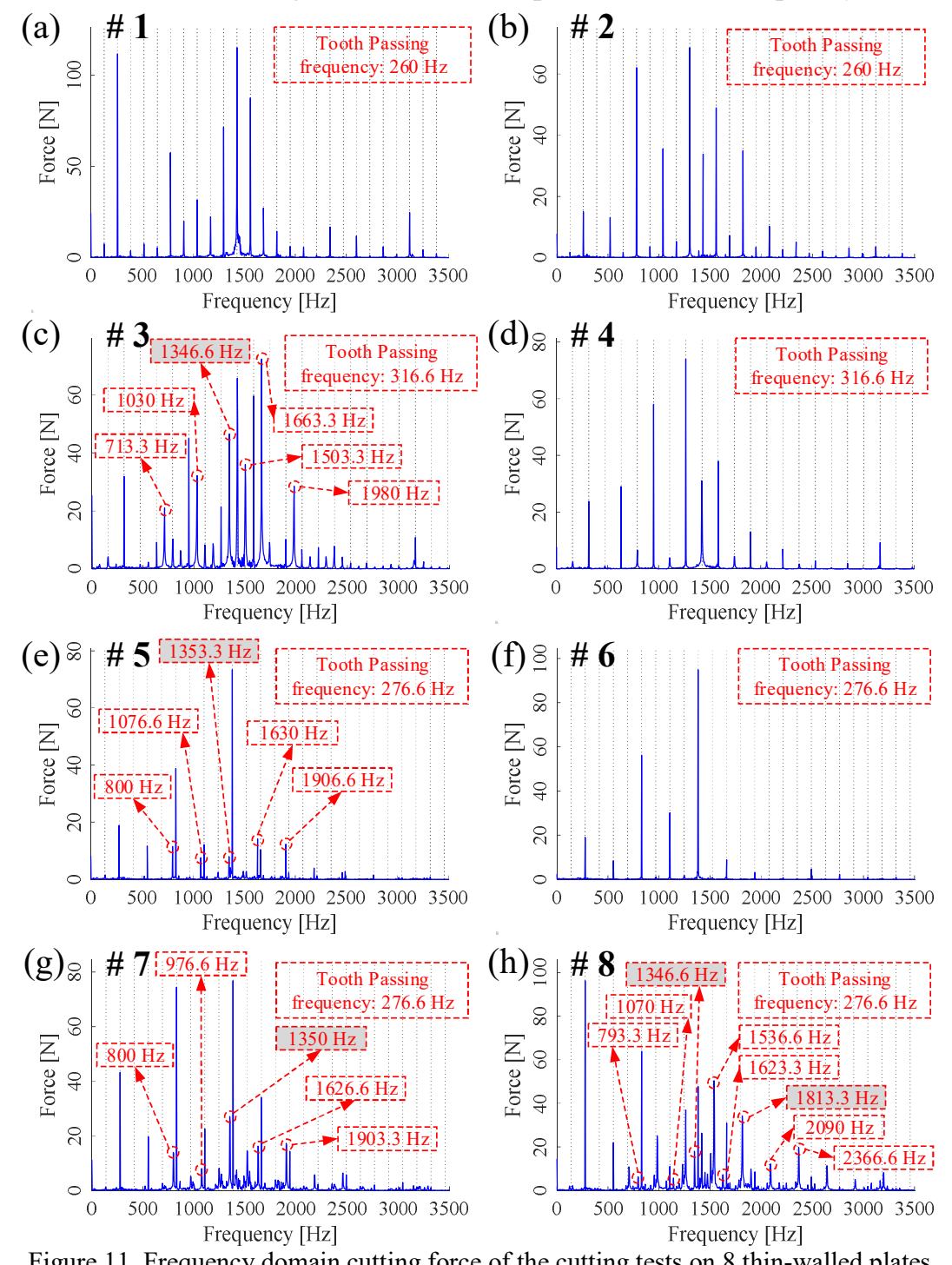

Figure 11 Frequency domain cutting force of the cutting tests on 8 thin-walled plates.

(a) \#1. (b) \#2. (c) \#3. (d) \#4. (e) \#5. (f) \#6. (g) \#7. (h) \#8. 
According to the machining surfaces shown in Figure 10 and the measured cutting forces in frequency domain shown in Figure 11, the cutting tests on thin-walled plates \#1, \#2, \#4 and \#6 are stable, while \#3, $\# 5, \# 7$ and $\# 8$ have chatter, which is in agreement with the simulation results. By comparing the frequency components of cutting force, the chatter frequency of cutting test on $\# 5$ and $\# 7$ are $1353.3 \mathrm{~Hz}$ and $1350 \mathrm{~Hz}$, respectively, which is close to the predictions $(1347 \mathrm{~Hz}$ and $1344 \mathrm{~Hz}$, respectively) shown in Figure 9. However, the measured chatter frequency in the cutting test on $\# 3$ is about $1346.6 \mathrm{~Hz}$ which is dominated by the first bending mode of the workpiece $(1336 \mathrm{~Hz})$, while the predicted chatter frequency is $1819 \mathrm{~Hz}$ caused by the second mode $(1798 \mathrm{~Hz})$. In the cutting test on \#8, there are two chatter frequencies $(1346.6$ $\mathrm{Hz}$ and $1813.3 \mathrm{~Hz})$ which are dominated by the first $(1336 \mathrm{~Hz})$ and the second $(1798 \mathrm{~Hz})$ mode of the workpiece, while the predicted chatter frequency is at $1339 \mathrm{~Hz}$ which is dominated by the first bending mode of the workpiece $(1336 \mathrm{~Hz})$. These differences may be caused by some nonlinear factors under unstable cutting conditions and process damping effect.

The vibrations at the cutting points are difficult to measure directly during machining tests, but an accelerometer is mounted at point 1 on the workpiece as shown in Figure 12.

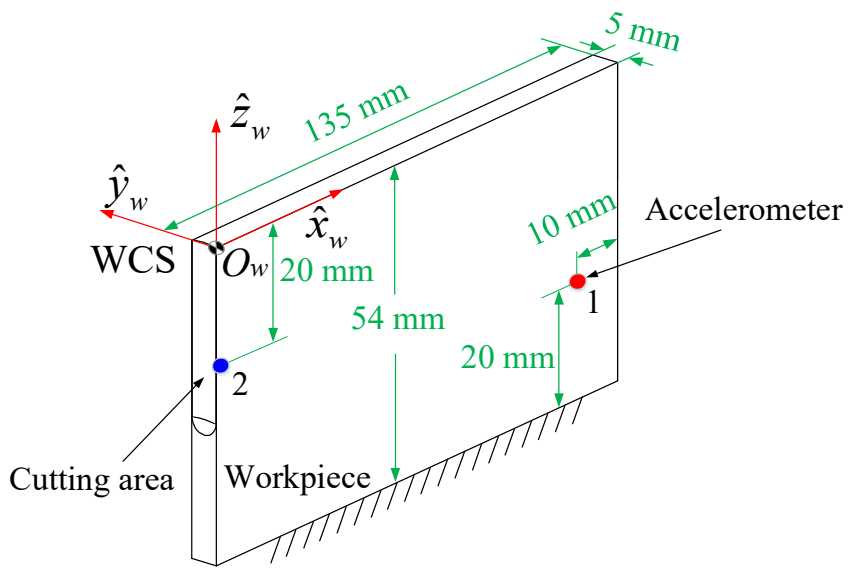

Figure 12 Experiment setup for vibration measurement for each thin-walled plate.

In order to calculate the vibrations at point 1 when the tool cuts at the point 2, their cross FRFs are measured and curve fitted with mass normalized mode shapes as listed in Table 5.

\begin{tabular}{|c|c|c|c|c|}
\hline Mode & $f_{n}[\mathrm{~Hz}]$ & $\zeta_{m}[\%]$ & $k_{m}[\mathrm{~N} / \mathrm{m}]$ & Mode Shape \\
\hline 1 & 1336 & 0.17 & $3.2315 \times 10^{7}$ & $\begin{array}{ll}\text { Point 1: } & 1.4817 \\
\text { Point 2: } & 3.0358\end{array}$ \\
\hline 2 & 1798 & 0.60 & $2.2107 \times 10^{7}$ & $\begin{array}{l}\text { Point 1: } 2.4031 \\
\text { Point 2: }-5.3894\end{array}$ \\
\hline 3 & 3141 & 1.68 & $5.6308 \times 10^{7}$ & $\begin{array}{ll}\text { Point 1: } & 2.6301 \\
\text { Point 2: } & 7.1926\end{array}$ \\
\hline
\end{tabular}

To verify the model of forced vibrations, four groups of stable cutting conditions shown in Figure 9 have been tested $(\Omega=6300 \mathrm{rpm}, f=1260 \mathrm{~mm} / \mathrm{min} ; \Omega=7300 \mathrm{rpm}, f=1460 \mathrm{~mm} / \mathrm{min} ; \Omega=8000 \mathrm{rpm}, f=1600$ $\mathrm{mm} / \mathrm{min} ; \Omega=8200 \mathrm{rpm}, f=1640 \mathrm{~mm} / \mathrm{min}$ ) with tool orientation angles $\mathrm{A}=-30^{\circ}$ and $\mathrm{C}=30^{\circ}$. When the tool was at point 2 , the accelerations at point 1 were measured and transformed to displacements by integrating the accelerations twice. The simulated and measured forced vibrations are in agreement as shown in Figure 13. 

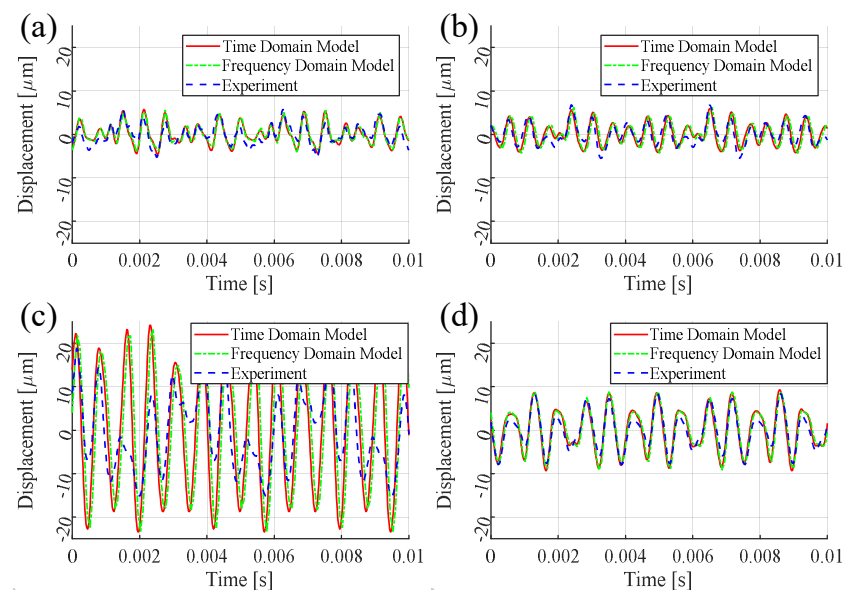

Figure 13 Forced vibrations at point 1 when the tool cutting at point 2 , where $\mathrm{A}=-30^{\circ}, \mathrm{C}=30^{\circ}$. (a) $\Omega=6300 \mathrm{rpm}, f=1260$ $\mathrm{mm} / \mathrm{min}$. (b) $\Omega=7300 \mathrm{rpm}, f=1460 \mathrm{~mm} / \mathrm{min}$. (c) $\Omega=8000 \mathrm{rpm}, f=1600 \mathrm{~mm} / \mathrm{min}$. (d) $\Omega=8200 \mathrm{rpm}, f=1640 \mathrm{~mm} / \mathrm{min}$.

The forced vibration algorithm requires feeedrate, spindle speed, tool geometry, the structural dynamics of tool and workpiece, cutting force coefficients, and the TWE. The forced vibration prediction model is verified at various feedrates and spindle speeds. The proposed algorithm is repeated at each tool position as TWE and structural dynamics of the flexible workpiece vary along the tool path within the virtual machining system (such as MACHPRO $^{\circledR}$ ).

\section{6) Conclusion}

The paper presents the general cutting dynamics model of five-axis ball-end milling of flexible, thinwalled workpiece. The cutting forces at the tool-workpiece engagement area are predicted by considering the general five-axis kinematics of the machine, tool center point motion and tool orientation along the tool path, and feed velocity distribution along the tool axis. The possibility of chatter occurrence at each discrete tool path position is evaluated by considering the regenerative chip thickness. The amplitudes of forced vibrations under chatter-free cutting conditions are also predicted along the tool path. The model allows digital testing and planning of ball-end milling operations ahead of costly physical trials. The accuracy of chatter prediction can be improved by considering the process damping effect as demonstrated in [31]. The model can also be extended to predict the surface location error and can be used to simulate the ball-end milling of highly flexible turbine blades.

\section{Acknowledgments}

This research is conducted at the Manufacturing Automation Laboratory, University of British Columbia. The research is supported by National Sciences and Research Council of Canada (NSERC) CANRIMT Grant NETGP 479639-15, National Natural Science Foundation of China (No. 51675417), National Key R\&D Program of China (No. 2018YFB1701901) and partially supported by China Scholarship Council (on behalf of the Chinese Ministry of Education).

\section{Appendix A. Screw axis}

$$
\boldsymbol{\xi}_{i}=\left[\begin{array}{c}
\omega_{i} \\
\mathbf{p}_{i}
\end{array}\right] \in \mathrm{IR}^{6}, i=1,2, \ldots, n-1 \text { is called the screw axis of joint } i \text { as expressed in fixed frame at zero }
$$

position, which can also be denoted as $\boldsymbol{\xi}_{i}=\left(\boldsymbol{\omega}_{i}, \mathbf{p}_{i}\right)$, while the matrix representation $\left[\boldsymbol{\xi}_{i}\right]$ of $\boldsymbol{\xi}_{i}=\left(\omega_{i}, \mathbf{p}_{i}\right)$ is: 


$$
\left[\boldsymbol{\xi}_{i}\right]=\left[\begin{array}{cc}
{\left[\boldsymbol{\omega}_{i}\right]} & \mathbf{p}_{i} \\
0 & 0
\end{array}\right] \in \operatorname{se}(3)
$$

Here, for a given vector $\boldsymbol{\omega}=\left[\omega_{1} \omega_{2} \omega_{3}\right]^{T} \in \mathbb{R}^{3}$, the symbol $[\cdot]$ is an operation defined as:

$$
[\boldsymbol{\omega}]=\left[\begin{array}{ccc}
0 & -\omega_{3} & \omega_{2} \\
\omega_{3} & 0 & -\omega_{1} \\
-\omega_{2} & \omega_{1} & 0
\end{array}\right] \in S o(3)
$$

which is a $3 \times 3$ skew-symmetric matrix representation of $\omega$ :

$$
[\omega]=-[\omega]^{T}
$$

The set of all real $3 \times 3$ skew-symmetric matrices is called $s o(3)$ while the set of all real $4 \times 4$ matrices which have the form like Eq.(58) is called $s e(3)^{[32]}$.

\section{References}

[1] Y. Altintas, P. Lee, Mechanics and dynamics of ball end milling, J. Manuf. Sci. Eng. 120 (1998) 684-692. https://doi.org/10.1115/1.2830207.

[2] G. Quintana, J. Ciurana, Chatter in machining processes: A review, Int. J. Mach. Tools Manuf. 51 (2011) 363-376. https://doi.org/10.1016/j.ijmachtools.2011.01.001.

[3] Y. Altintas, Manufacturing automation: Metal cutting mechanics, machine tool vibrations, and CNC design, Cambridge University Press, Cambridge University Press, NY, USA, 2012. https://doi.org/10.1115/1.1399383.

[4] J. Tlusty, W. Zaton, F. Ismail, Stability lobes in milling, CIRP Ann. - Manuf. Technol. 32 (1983) 309-313. https://doi.org/10.1016/S0007-8506(07)63411-8.

[5] Y. Altintas, E. Budak, Analytical prediction of stability lobes in milling, CIRP Ann. 44 (1995) 357-362. https://doi.org/10.1016/S0007-8506(07)62342-7.

[6] T. Insperger, G. Stépán, Updated semi-discretization method for periodic delay-differential equations with discrete delay, Int. J. Numer. Methods Eng. 61 (2004) 117-141.

https://doi.org/10.1002/nme.1061.

[7] Y. Ding, L. Zhu, X. Zhang, H. Ding, A full-discretization method for prediction of milling stability, Int. J. Mach. Tools Manuf. 50 (2010) 502-509. https://doi.org/10.1016/J.IJMACHTOOLS.2010.01.003.

[8] Y. Altintas, E. Shamoto, P. Lee, E. Budak, Analytical prediction of stability lobes in ball end milling, J. Manuf. Sci. Eng. 121 (1999) 586-592. https://doi.org/10.1115/1.2833064.

[9] J. Zhang, J. Li, Z. Xie, C. Du, L. Gui, W. Zhao, Rapid dynamics prediction of tool point for birotary head five-axis machine tool, Precis. Eng. 48 (2017) 203-215.

https://doi.org/10.1016/j.precisioneng.2016.12.003.

[10] T.L. Schmitz, Predicting high-speed machining dynamics by substructure analysis, CIRP Ann. Manuf. Technol. 49 (2000) 303-308. https://doi.org/10.1016/S0007-8506(07)62951-5.

[11] L.T. Tunc, E. Budak, Extraction of 5-axis milling conditions from CAM data for process simulation, Int. J. Adv. Manuf. Technol. 43 (2009) 538-550. https://doi.org/10.1007/s00170-0081735-7.

[12] E. Ozturk, E. Budak, Dynamics and stability of five-axis ball-end milling, J. Manuf. Sci. Eng. 132 (2010) 237-247. https://doi.org/10.1115/1.4001038.

[13] O. Tuysuz, Y. Altintas, Analytical modeling of process damping in machining, J. Manuf. Sci. Eng. 141 (2019). https://doi.org/10.1115/1.4043310.

[14] C. Sun, Y. Altintas, Chatter free tool orientations in 5-axis ball-end milling, Int. J. Mach. Tools Manuf. 106 (2016) 89-97. https://doi.org/10.1016/j.ijmachtools.2016.04.007. 
[15] K. Ringgaard, Y. Mohammadi, C. Merrild, O. Balling, K. Ahmadi, Optimization of material removal rate in milling of thin-walled structures using penalty cost function, Int. J. Mach. Tools Manuf. 145 (2019) 103430. https://doi.org/10.1016/j.ijmachtools.2019.103430.

[16] J. Yang, D. Aslan, Y. Altintas, Identification of workpiece location on rotary tables to minimize tracking errors in five-axis machining, Int. J. Mach. Tools Manuf. 125 (2018) 89-98. https://doi.org/10.1016/j.ijmachtools.2017.11.009.

[17] J. Denavit, R.S. Hartenberg, A kinematic notation for lower-pair mechanisms based on matrices, J. Appl. Mech. (1955) 215-221.

[18] K.M. Lynch, F.C. Park, Modern robotics mechanics, planning, and control, Cambridge University Press, 2017. http://hades.mech.northwestern.edu/index.php/Modern Robotics.

[19] J. Yang, Y. Altintas, Generalized kinematics of five-axis serial machines with non-singular tool path generation, Int. J. Mach. Tools Manuf. 75 (2013) 119-132. https://doi.org/10.1016/j.ijmachtools.2013.09.002.

[20] R.M. Murray, Z. Li, S.S. Sastry, A mathematical introduction to robotic manipulation, CRC Press, CRC Press, 1994. http://www.crcpress.com/product/isbn/9780849379819.

[21] O. Tuysuz, Modeling of machining thin-walled aerospace structures, University of British Columbia, 2018. https://doi.org/10.14288/1.0373471.

[22] Z.M. Kilic, Y. Altintas, Generalized modelling of cutting tool geometries for unified process simulation, Int. J. Mach. Tools Manuf. 104 (2016) 14-25. https://doi.org/10.1016/J.JJMACHTOOLS.2016.01.007.

[23] Manufacturing Automation Lab. Inc., MACHPRO, (2018). www.malinc.com/products/machpro.

[24] P. Lee, Y. Altintas, Prediction of ball-end milling forces from orthogonal cutting data, Int. J. Mach. Tools Manuf. 36 (1996) 1059-1072. https://doi.org/10.1016/0890-6955(95)00081-X.

[25] Z.M. Kilic, Y. Altintas, Generalized mechanics and dynamics of metal cutting operations for unified simulations, Int. J. Mach. Tools Manuf. 104 (2016) 1-13. https://doi.org/10.1016/J.IJMACHTOOLS.2016.01.006.

[26] S. Engin, Y. Altintas, Mechanics and dynamics of general milling cutters.Part I: helical end mills, Int. J. Mach. Tools Manuf. 41 (2001) 2195-2212. https://doi.org/10.1016/S0890-6955(01)000451.

[27] M. Eynian, Chatter stability of turning and milling with process damping, University of British Columbia, 2010. https://doi.org/10.14288/1.0069056.

[28] W.B. Ferry, Y. Altintas, Virtual Five-Axis Flank Milling of Jet Engine Impellers-Part I: Mechanics of Five-Axis Flank Milling, J. Manuf. Sci. Eng. 130 (2008) 011005. https://doi.org/10.1115/1.2815761.

[29] Y. Altintas, J. Yang, Z.M. Kilic, Virtual prediction and constraint of contour errors induced by cutting force disturbances on multi-axis CNC machine tools, CIRP Ann. 68 (2019) 377-380. https://doi.org/10.1016/j.cirp.2019.04.019.

[30] Manufacturing Automation Lab. Inc., CUTPRO, Advanced Milling Process Simulation System, (2001). https://www.malinc.com/products/cutpro/.

[31] Y. Altintas, M. Eynian, H. Onozuka, Identification of dynamic cutting force coefficients and chatter stability with process damping, CIRP Ann. - Manuf. Technol. 57 (2008) 371-374. https://doi.org/10.1016/j.cirp.2008.03.048.

[32] F.C. Park, J.E. Bobrow, S.R. Ploen, A lie group formulation of robot dynamics, Int. J. Rob. Res. 14 (1995) 609-618. https://doi.org/10.1177/027836499501400606. 


\section{Table caption list}

Table 1. Angles of two rotary axes and tool axis vectors for different tool orientations.

Table 2. Modal parameters of tool in TCS.

Table 3. Modal parameters of cantilevered plates in $\hat{y}_{w}$ direction at the origin of WCS shown in Figure 7.

Table 4. Cutting parameters for 8 thin-walled Al6061 plates. Tool: A 2 fluted ball-end mill with $12 \mathrm{~mm}$ diameter and $30^{\circ}$ helix angle. Workpiece: Al 7050-T7451.

Table 5. Identified modal parameters between point 1 and 2.

\section{Figure caption list}

Figure 1. A-C type table-tilting five-axis machine tool. (a) Global view of the machine tool. (b) Partial enlarged view of the tool.

Figure 2. Tool-workpiece engagement on Work (WCS) and Engagement (ECS) coordinate systems.

Figure 3. Envelope of ball-end mill. (a) Isometric view. (b) Top view.

Figure 4. Flow chart for the chatter stability and forced vibration estimations of five-axis ball-end milling process.

Figure 5. The orientation of the tool related to the workpiece with different $\mathrm{A} / \mathrm{C}$ angles. (a) $\mathrm{A}=-30^{\circ}, \mathrm{C}=30^{\circ}$. (b) $\mathrm{A}=-30^{\circ}, \mathrm{C}=60^{\circ}$. (c) $\mathrm{A}=-30^{\circ}, \mathrm{C}=90^{\circ}$. (d) $\mathrm{A}=-60^{\circ}, \mathrm{C}=30^{\circ}$. (e) $\mathrm{A}=-60^{\circ}, \mathrm{C}=60^{\circ}$. (f) $\mathrm{A}=-60^{\circ}, \mathrm{C}=90^{\circ}$.

Figure 6. FRFs of the tool measured in TCS.

Figure 7. Workpiece for experiment.

Figure 8. Tool-workpiece engagements for the tool paths with different $A / C$ angles. (a) $A=-30^{\circ}, C=30^{\circ}$. (b) $\mathrm{A}=-30^{\circ}, \mathrm{C}=60^{\circ}$. (c) $\mathrm{A}=-30^{\circ}, \mathrm{C}=90^{\circ}$. (d) $\mathrm{A}=-60^{\circ}, \mathrm{C}=30^{\circ}$. (e) $\mathrm{A}=-60^{\circ}, \mathrm{C}=60^{\circ}$. (f) $\mathrm{A}=-60^{\circ}, \mathrm{C}=90^{\circ}$.

Figure 9. Sweeping the spindle speed for chatter stability prediction with different $A / C$ angles. (a) $A=-30^{\circ}$, $\mathrm{C}=30^{\circ}$. (b) $\mathrm{A}=-30^{\circ}, \mathrm{C}=60^{\circ}$. (c) $\mathrm{A}=-30^{\circ}, \mathrm{C}=90^{\circ}$. (d) $\mathrm{A}=-60^{\circ}, \mathrm{C}=30^{\circ}$. (e) $\mathrm{A}=-60^{\circ}, \mathrm{C}=60^{\circ}$. (f) $\mathrm{A}=-60^{\circ}, \mathrm{C}=90^{\circ}$.

Figure 10. The machined surfaces of the 8 thin-walled plates. (a)\#1. (b) \#2. (c)\#3. (d) \#4. (e)\#5. (f) \#6. (g) \#7. (h) \#8.

Figure 11. Frequency domain cutting force of the cutting tests on 8 thin-walled plates. (a) \#1. (b) \#2. (c) \#3. (d) \#4. (e) \#5. (f) \#6. (g) \#7. (h) \#8.

Figure 12. Experiment setup for vibration measurement for each thin-walled plate.

Figure 13. Forced vibrations at point 1 when the tool cutting at point 2 , where $\mathrm{A}=-30^{\circ}, \mathrm{C}=30^{\circ}$. (a) $\Omega=6300$ $\mathrm{rpm}, f=1260 \mathrm{~mm} / \mathrm{min}$. (b) $\Omega=7300 \mathrm{rpm}, f=1460 \mathrm{~mm} / \mathrm{min}$. (c) $\Omega=8000 \mathrm{rpm}, f=1600 \mathrm{~mm} / \mathrm{min}$. (d) $\Omega=8200$ $\mathrm{rpm}, f=1640 \mathrm{~mm} / \mathrm{min}$. 